\title{
Ultrasonografía focalizada en situaciones de urgencia
}

\author{
Focus ultrasound in emergency
}

Luis Azócar Ceballos'ㄹ, Vanessa Vásquez Stuardo²

\begin{abstract}
"Point of Care Ultrasonography" offers numerous clinical advantages in guiding patient management by answering specific questions and as a support tool for invasive procedures. By avoiding unnecessary transfers and more complex examinations, it also has logistical benefits. Its use has spread beyond the field of radiology to various medical specialties, constituting a valuable tool for anesthetic work. Patients in emergency care are one of the several groups that benefit from this relatively new tool that allows to complement the clinical examination of the patient by providing additional information after the physical examination. To optimize its use, it is necessary to know some basic concepts of ultrasound physics, as well as types of transducers, ultrasound modalities, terminology and some concepts of obtaining images (window, plane, vision). The ultrasound-guided procedures for vascular access and some ultrasound-assisted examinations are described. Besides, a brief description of the FOCUS Echocardiography (Focus Oriented Cardiac Ultrasound) is given, as there is a special article for it. Pleural, full stomach, extended FAST, resuscitation, airway and optic nerve ultrasonographies are described with further detail. Finally, some simple and validated protocols for the use of anesthesiologists, emergency physicians and intensivists are listed and briefly described, which make this technique ideal for use at the bedside in time-dependent situations: FOCUS, FAST, RUSH, ACES FATE, BLUE, FALL and FEEL.
\end{abstract}

\section{RESUMEN}

La "ultrasonografía en el punto de atención" ofrece numerosas ventajas clínicas al orientar el manejo del paciente al responder preguntas concretas y como herramienta de apoyo para procedimientos invasivos. También presenta ventajas logísticas al evitar traslados innecesarios y exámenes más complejos. Su uso se ha extendido más allá del campo de la radiología a diversas especialidades médicas, constituyendo una herramienta valiosa para el quehacer anestésico. Los pacientes en situaciones de urgencia son uno de tantos grupos beneficiados con esta relativamente nueva herramienta, permitiendo complementar el examen clínico del paciente, profundizando la información que entrega el examen físico. Para optimizar su utilización es necesario conocer algunos conceptos básicos de física del ultrasonido, tipos de transductores, modalidades

Clínica Dávila.

Hospital de Urgencia Asistencia Pública, Clínica Dávila.

Fecha de recepción: 26 de noviembre de 2020

Fecha de aceptación:

\section{ORCID}

0000-0002-0079-1303

\section{Correspondencia:}


ecográficas, terminología y algunos conceptos de obtención de imágenes (ventana, plano, visión). Se describe el procedimientos ecoguiado para accesos vasculares y algunos exámenes asistidos con ultrasonografía. Brevemente la ecocardiografía FOCUS (Focus Oriented Cardiac Ultrasound), pues hay un artículo especial para ello. Más detalladamente: ultrasonografía pleural, en estómago lleno, FAST extendido, en resucitación, en la vía aérea y en el nervio óptico. Finalmente, se enumeran y describen escuetamente algunos protocolos sencillos y validados para el uso de anestesiólogos, emergenciólogos e intensivistas, que hacen que esta técnica sea idónea para usar a la cabecera del paciente en situaciones tiempo dependientes: FOCUS, FAST, RUSH, ACES FATE, BLUE, FALL y FEEL.

concepto POCUS (acrónimo del inglés: Point Of Care UltraSound) cuya traducción al castellano puede interpretarse como "ultrasonido en el punto de atención", puede tener dos interpretaciones: la primera es el uso de la ecografía en el lugar de atención del paciente, es decir, se lleva el ecógrafo al lugar donde se encuentra el enfermo sin necesidad de movilizar a éste hacia un Servicio de Radiología; la segunda es el uso de la ecografía como método de verificación de un determinado diagnóstico. En este caso es necesario que previamente, el médico a cargo del paciente, a través de la historia clínica, el examen físico y exámenes complementarios, se haya formado una impresión diagnóstica y/o etiológica que deba confirmar o descartar a través del uso de la ecografía. Es decir, en este caso el concepto "atención" dice relación con algún aspecto del cuadro clínico que le "llamó la atención al médico" y que debe corroborar o desechar, para decidir el manejo clínico más adecuado.

El uso de POCUS se ha ido extendiendo en las distintas especialidades médicas, principalmente medicina de urgencia y cuidados intensivos. El presente artículo tiene por objeto dar a conocer al lector los usos más relevantes del ultrasonido (US) en la práctica anestesiológica actual y la importancia de su aplicación enfocada en urgencia y trauma. Se trata de una herramienta que permite complementar el examen clínico del paciente, profundizando la información que entrega el examen físico.

El US tiene utilidad en casos específicos como se verá más adelante, pero en rigor se puede utilizar para evaluar a cualquier paciente, puesto que se realiza junto a la cama del paciente, no es un método invasivo, implica costos adicionales menores, salvo el costo del equipo y la capacitación en su uso y se puede repetir las veces que sea necesario. Además, disminuye traslados a servicios radiológicos, especialmente en caso de pacientes con inestabilidad hemodinámi$\mathrm{ca}$, disminuyendo riesgos y postergaciones en la realización del examen por condiciones de agenda de servicios distintos a aquel donde se atiende el paciente. Igualmente, no requiere de ambientes silenciosos y se puede utilizar en un helicóptero o una ambulancia en el contexto de medicina prehospitalaria. Ocasionalmente puede haber hallazgos incidentales de patologías por medio de este examen (ejemplos: nódulo tiroideo, hidronefrosis, litiasis vesical, etc.), pero en este caso éste no es su objetivo. Sus principales limitaciones son: el posible acceso restringido a la zona a examinar por apósitos, campos quirúrgicos, enfisema subcutáneo y poca colaboración del paciente.

\section{Conceptos básicos de ultrasonografía}

Para entender cómo fenómenos físicos logran producir una imagen similar a la anatómica en una pantalla y obtener el óptimo rendimiento de este proceso, se deben tener presentes algunos conceptos básicos relevantes[2]. Así, antes que todo, definiremos ultrasonido como aquel sonido que tiene una frecuencia mayor de la que puede ser oída por los seres humanos[1] y que posee las características físicas del comportamiento de una onda. Por lo mismo, se puede definir distintas variables, tales como:

Frecuencia (f): número de ciclos por unidad de tiempo. Se mide en número de ciclos por segundo, denominados hercios $(\mathrm{Hz})$. El ultrasonido tiene una frecuencia mayor a $20.000 \mathrm{~Hz}$. El usado en clínica está en el rango de 2 a 15 megahercios ( $\mathrm{MHz}$ ).

Longitud de onda $(\lambda)$ : distancia que recorre un ciclo en un medio. En el caso del ultrasonido se mide en milímetros ( $\mathrm{mm}$ ).

Amplitud: es la altura máxima de una onda; hace referencia a la intensidad del sonido. Se mide en decibelios (dB).

Velocidad de propagación (c): varía según el tejido del que se trate, desde $1.470 \mathrm{~mm} \cdot \mathrm{s}^{-1}$ en la grasa, hasta $1.568 \mathrm{~mm} \cdot \mathrm{s}^{-1}$ en el músculo. A modo de convención para el tejido total se considera una velocidad constante de $1.540 \mathrm{~mm} \cdot \mathrm{s}^{-1}$.

Las variables mencionadas anteriormente interactúan según la siguiente ecuación:

$$
c=f x \lambda
$$


Así podemos observar que frecuencia y longitud de onda varían de forma inversamente proporcional: a mayor frecuencia, menor longitud de onda y viceversa.

Con respecto a la velocidad de propagación de las ondas, ésta es constante en un medio uniforme. Sin embargo, su amplitud y poder disminuyen progresivamente, conforme penetra en profundidad, fenómeno que recibe el nombre de atenuación, lo cual implica, que a determinada distancia la onda tendrá una amplitud de $0 \mathrm{~dB}$. La atenuación es directamente proporcional a la distancia recorrida, la frecuencia de la onda y la densidad del medio. A mayor frecuencia de onda, por lo tanto, se obtendrán imágenes de menor profundidad.

Otro concepto importante es la resolución de la imagen, la que se define como la capacidad de reconocer como independientes dos puntos muy próximos o como la mínima separación que deben tener dos estructuras para ser identificadas visualmente como diferentes. Por lo tanto, mientras mayor resolución tenga un equipo, más estructuras podrá diferenciar y con mayor detalle. Diferenciamos entre resolución axial o longitudinal (paralela al eje del US) la que se mantiene constante en todo el recorrido del haz y resolución lateral (perpendicular al eje del US) la que es mejor al centro del haz y disminuye progresivamente hacia la divergencia de éste. En términos generales, factores que hacen aumentar la resolución de un aparato son: el aumento de la frecuencia, el aumento de la ganancia y la disminución de la longitud de onda.

En nuestra práctica diaria e integrando lo anterior, obtendremos una imagen de mejor resolución (con más detalle) si acotamos la profundidad de nuestro examen a lo indispensable para observar nuestro objetivo trabajando con mayor frecuencia y centramos este bajo el haz de ultrasonido.

Los transductores de ultrasonido son dispositivos que contienen una serie de cristales piezoeléctricos que son los que emiten $\boldsymbol{y}$ reciben ondas de sonido que viajan a través de los tejidos blandos[3]. Así, los diferentes tejidos tienen capacidad para reflejar o refractar las ondas emitidas por un transductor de ultrasonido que capta los ecos de estas estructuras de vuelta para representarlos en forma de una imagen en gama de grises, de forma proporcional a la intensidad de la reflexión, según su frecuencia y el tiempo en que son detectados[1]. Estos ciclos se repiten en forma constante[2].

Existen diferentes tipos de transductores según la frecuencia a la cual emiten el US y punto desde que se emiten las ondas (Figura 1), los de mayor uso en anestesia son:

- Lineal.

- Sectorial (también llamado "phased array" en inglés).

- Convexo.

El transductor lineal, de mayor frecuencia, se usa habitualmente para evaluar estructuras superficiales (a menos de $7 \mathrm{~cm}$ de profundidad) como es el caso de nervios y vasos sanguíneos. Emite y recibe frecuencias que oscilan habitualmente entre los 5-13 MHz y en algunos casos hasta $20 \mathrm{MHz}$. Por el contrario, los transductores sectorial y convexo emiten menor frecuencia (1-5 MHz) y se utilizan para evaluar estructuras más profundas. La diferencia entre éstos radica en el punto de partida de las ondas. En el sectorial parten se emite desde una superficie muy reducida, un punto único, desde el que las ondas se expanden dando una imagen en abanico, lo que los hace especialmente útiles para evitar las costillas y el artefacto que generan en el examen ultrasonográfico transtorácico del corazón. En el convexo se emiten ondas desde una superficie mayor dando una imagen más similar a un trapecio, por lo que se utiliza principalmente para estudiar la cavidad abdominal, aunque puede utilizarse también para examen de tórax. De hecho, existen protocolos que lo consideran como transductor único para ventanas toráxicas y abdominales en contextos tiempo dependientes en los que el cambio de transductor enlentece el procedimiento (ejemplo: eFAST).

El transductor, al actuar también como receptor, pesquisará ecos de diferentes amplitudes dependiendo de la ecodensidad de los objetos con respecto al medio. Además, el tiempo transcurrido entre la emisión y la recepción del haz, permite conocer la distancia de estos objetos con respecto al transductor. Con estos dos parámetros se puede comenzar a realizar representaciones visuales del sector explorado y así hablar de las modalidades ecográficas que son 4: modo A (amplitud), modo B (brillo), modo M (movimiento) y visualización en tiempo real (1).

- Modo A (modulación de amplitud): es el primero que se desarrolló y en la actualidad tiene escasas aplicaciones clínicas.

- Modo B (modulación del brillo): la señal de ultrasonido reflejada por estructuras se muestra como puntos que brillan con una intensidad proporcional a la del eco. El modo B compuesto (modo 2D o bidimensional) incorpora el almacenamiento de los puntos B mientras se mueve el transductor, lo que da lugar a una imagen constituida por muchas líneas individuales en modo $B$ simple (imagen bidimensional estática). El modo B 


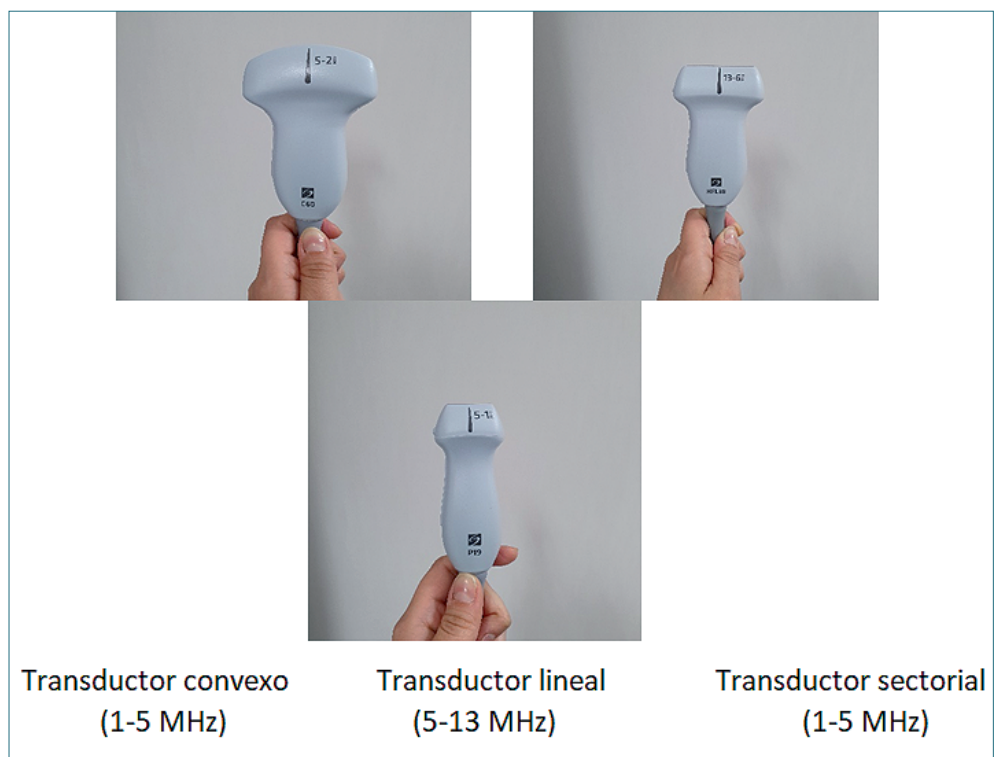

Figura 1. Distintos tipos de transductores.

es la base de toda exploración ecográfica; sobre él se activa el resto de modos de ecografía (modo M, Doppler color, doppler pulsado y doppler continuo).

- Modo M (time motion mode): es una variante del modo B compuesto, en la que se utiliza un solo haz de ultrasonido para obtener imágenes unidimensionales (una línea de puntos) en movimiento. Muestra lo que hay en la línea que atraviesa. Se presenta en un trazado continuo sobre dos ejes: en el eje vertical se dispone la línea de puntos y en el horizontal, el tiempo. Permite medir con precisión los diámetros de las cavidades y los grosores de las paredes en cada momento del ciclo cardiaco e identificar movimientos anormales (válvulas, paredes ventriculares).

- Visualización en tiempo real: es el modo B dinámico y en la actualidad el más usado en clínica. Proporciona una imagen dinámica de alta calidad de las estructuras en estudio. La imagen se forma por la emisión de un número elevado de líneas de barrido $B$ por unidad de tiempo, de manera que el ojo humano la percibe como una imagen en movimiento. Permite estudiar estructuras en continuo movimiento como las paredes del corazón y las válvulas cardiacas.

Otra herramienta muy útil en ecografía es el doppler, que se basa en el principio que describe el cambio de frecuencia que se produce en un sonido cuando existe movimiento relativo entre la fuente emisora y el receptor. En clínica se utiliza especialmente para determinar el movimiento de los glóbulos rojos. Existe Doppler pulsado y color para flujos de baja velocidad y, doppler continuo para flujos de alta velocidad[1]. Su estudio en profundidad excede los objetivos de este artículo.

Las imágenes obtenidas pueden optimizarse realizando diversos ajustes ofrecidos por el equipo del que dispongamos. Algunas de estas opciones son: ganancia, compresión, profundidad, ancho, compensación de ganancia temporal, foco, zoom, etc. A modo de ejemplo, la ganancia es un ajuste que se puede hacer con el ecógrafo para compensar la atenuación que sufren las ondas al atravesar los tejidos, especialmente panículos adiposos gruesos. Esta modalidad amplifica artificialmente todos los ecos que recibe, añadiendo unos decibelios determinados a toda onda reflejada sin aumentar realmente su potencia de salida. Por otra parte, la ganancia temporal es un ajuste realizado con deslizadores (a modo de un ecualizador de un equipo musical de alta fidelidad) en forma selectiva a diferentes profundidades del tejido estudiado, pudiendo ampliar las señales bajo un tejido de alta impedancia o disminuir señales muy potentes a nivel de tejidos superficiales. El correcto conocimiento de nuestros equipos facilita su uso optimizado.

Otro concepto básico importante es la terminología a emplear en cuanto al uso de los transductores al momento del examen mismo y sobre la obtención de imágenes desde nuestros pacientes. Así, Zimmer- 
man et al.[4] describen los siguientes conceptos:

Indicador: (Figura 2) También llamado notch o marcador, se trata de un punto o relieve en un lado del transductor que coincide con un marcador en la pantalla y sirve para orientar.

Deslizamiento (sliding): Es el movimiento del transductor a una posición distinta en el cuerpo. Se describe también como "window shopping". Sirve para encontrar la mejor posición para la imagen, por ejemplo, entre distintos espacios intercostales.

Inclinación (tilting): Movimiento que se realiza manteniendo el transductor en la misma parte del cuerpo y aplicando un balanceo para mostrar distintas estructuras en el mismo plano. El balanceo se realiza en el eje ancho del transductor, inclinando el extremo distal (la cola) de este hacia los lados.

Angulación: Movimiento que se realiza manteniendo el transductor en la misma parte del cuerpo y aplicando un balanceo que lleva la cola del transductor hacia delante y atrás para crear nuevos planos de imágenes relativamente paralelos al plano original. Es perpendicular al tilting.

Rotación: la sonda mantenida en un punto se gira sobre su eje central como una llave en la cerradura.

En cuanto a la obtención de imágenes se describirán algunos conceptos, principalmente referidos a examen cardiaco (aunque no exclusivamente):

Ventana: es usada para describir la localización del transductor de ultrasonido. Es el punto donde situamos el transductor para ver una estructura en general referida al corazón. En el examen cardiaco

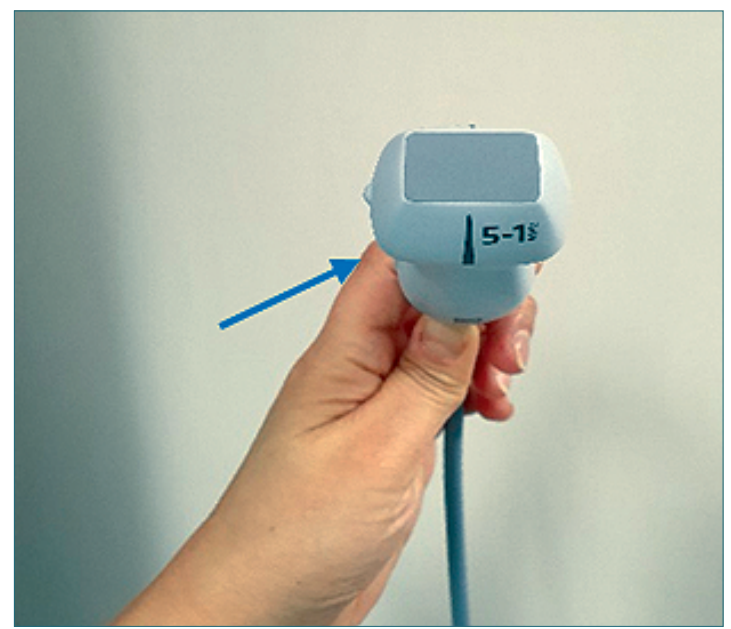

Figura 2. La flecha señala el indicador de un transductor sectorial (1-5 MHz). transtoráxico, por ejemplo, se describen 3 ventanas: paraesternal, apical y subcostal.

Plano: Se refiere al plano anatómico o sección transversal que corta el haz de ultrasonido. En ecocardiografía se trabaja con eje largo y eje corto.

Visión: Es una combinación de ventana con plano que se usa para describir una imagen particular, por ejemplo, eje largo paraesternal.

\section{Utilidad clínica de la ecografía}

La utilidad que presta la ecografía para el anestesiólogo se puede resumir en dos tipos de exploraciones: procedimientos guiados por ecografías y exámenes asistidos por ecografía[5].

\section{Procedimientos ecoguiados}

\section{Accesos vasculares}

Principalmente utilizado para la instalación de catéteres venosos centrales. Se ha descrito disminución en el tiempo de realización del procedimiento, menor número de punciones, menor tasa de fallas, de complicaciones precoces y de infecciones[6],[7] (Figura 3). La incidencia reportada de complicaciones por punción venosa central bajo eco es de $4,6 \%$, mientras que con la técnica tradicional utilizando referencias anatómicas es de $10,5 \%$, lo que significa una reducción del riesgo absoluto del 59\%[7],[8]. Hoy en día el uso de US para cateterización central está considerado como estándar de cuidado[9]. Antes de instalar el campo estéril es recomendable hacer un mapeo ecográfico en busca de las venas susceptibles de albergar un catéter venoso central, para así poder anticipar alguna dificultad durante el procedimiento (hematomas por punciones anteriores o presencia de trombos intravasculares), así como alteraciones anatómicas no sospechadas (vasos aberrantes). La recomendación actual es efectuar la punción en tiempo real (en vez de solamente marcar con US y luego puncionar sin observar las imágenes) y en eje corto. También se ha usado con éxito para punciones venosas periféricas, especialmente en pacientes obesos, deshidratados y en niños.

En la instalación de líneas arteriales también se ha descrito una mayor tasa de éxito al primer intento, menor tiempo de realización y menor incidencia de hematomas[10]. En un metaanálisis de Wan-Jie Gu y cols.[11] se recomienda el uso de US en tiempo real para realizar cateterizaciones arteriales. Dicho estudio no muestra diferencia entre hacerlo en eje corto (fuera de plano) o eje largo (en plano). La recomendación 
actual enfatiza el uso del US desde el inicio del procedimiento y no como rescate ante la falla de la técnica tradicional por palpación.

\section{Exámenes asistidos por ecografía}

Aquí se hará referencia a una serie de protocolos de uso de ecografía para poder contestar preguntas específicas según el órgano o sistema que se está estudiando.

\section{Ecocardiografía FOCUS (Focus Oriented Cardiac Ultrasound)}

Es importante aclarar que el US focalizado se utiliza para profundizar y complementar la información obtenida mediante la evaluación clínica y que no es un método que deba usarse para efectuar un diagnóstico morfofuncional detallado, lo que requiere de una ecocardiografía practicada formalmente por un cardiólogo. En el caso del protocolo focus se describirá la manera de obtener ventanas básicas[12] (Figura 4):

- Paraesternal Izquierda en eje largo y corto.

- Apical.

- Subcostal en eje transversal (cardíaco) y eje longitudinal (vena cava inferior).

Habitualmente, se obtienen estas imágenes con un transductor sectorial (phased array). Los equipos portátiles tienen una menor resolución que los equipos de alta gama, por lo que están en desventaja para evaluar detalles puntuales como son algunas alteraciones valvulares menores. Por lo tanto, como ya fue dicho, el FOCUS no reemplaza a una ecocardiografía formal y ésta debiese solicitarse cuando se encuentre alguna alteración que amerite manejo cardiológico[13]. Se recomienda el FOCUS para evaluar[14]:

- Tamaño y función sistólica del ventrículo izquierdo (VI).

- Función sistólica del ventrículo derecho (VD). Normalmente el tamaño del VD es de aproximadamente $2 / 3$ del tamaño del VI en su diámetro basal. Un VD disfuncional suele estar dilatado y por ende, se altera la relación de tamaño respecto del $\mathrm{VI}$.

- Volemia: evaluando el vaciamiento de cámara del fin de sístole ventricular y también midiendo la colapsabilidad de la vena cava inferior.

- Derrame pericárdico y/o taponamiento cardiaco.

- También se utiliza la ventana subcostal (igualmente llamada subxifoídea) en el contexto de la reanimación cardiopulmonar para poder evaluar directamente si el corazón tiene o no actividad.

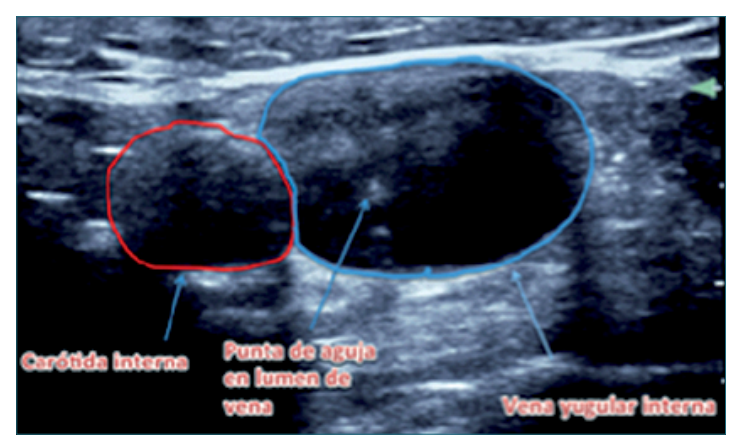

Figura 3. Punción yugular en eje corto.

Se realiza una observación que no debiera tomar más de 5 segundos para no retardar innecesariamente el masaje cardíaco.

En el protocolo FOCUS estas apreciaciones son visuales, sin mediciones objetivas ni uso de doppler, por lo que se requiere de práctica continuada para obtener un mínimo de destreza y experiencia en interpretar las imágenes (a lo menos 20 a 30 procedimientos). Al respecto no hay acuerdo generalizado en la literatura[15].

\section{US pleural}

A diferencia de otros abordajes, en el US pleural normal sólo se pueden apreciar estructuras anatómicas que están superficiales en relación con la línea de la pleura (como músculos pectorales, serratos, intercostales y costillas), la que se aprecia como una línea hiperecogénica justo bajo las costillas, corresponde a la reflexión producida por ambas pleuras (o solamente la pleura parietal en caso de neumotórax como se verá más adelante). En un plano más profundo a la línea pleural normalmente no se ven estructuras anatómicas, solo se ven artefactos, que son el objeto de atención de esta modalidad de US. El pulmón se hace visible solamente cuando pierde aire, ejemplo: condensaciones, atelectasias. Así los artefactos básicos a reconocer son[16]:

1. Líneas A: que corresponden a una imagen reiterada de la línea pleural provocada por una reverberación de las ondas de US entre el transductor y las pleuras, que se muestran en la imagen como líneas horizontales repetidas a intervalos similares (Figura 5).

2. Líneas B: se trata de líneas hiperecogénicas que aparecen a partir de la línea pleural hasta el extremo inferior de la pantalla, con forma de colas de cometa que se mueven por el deslizamiento 


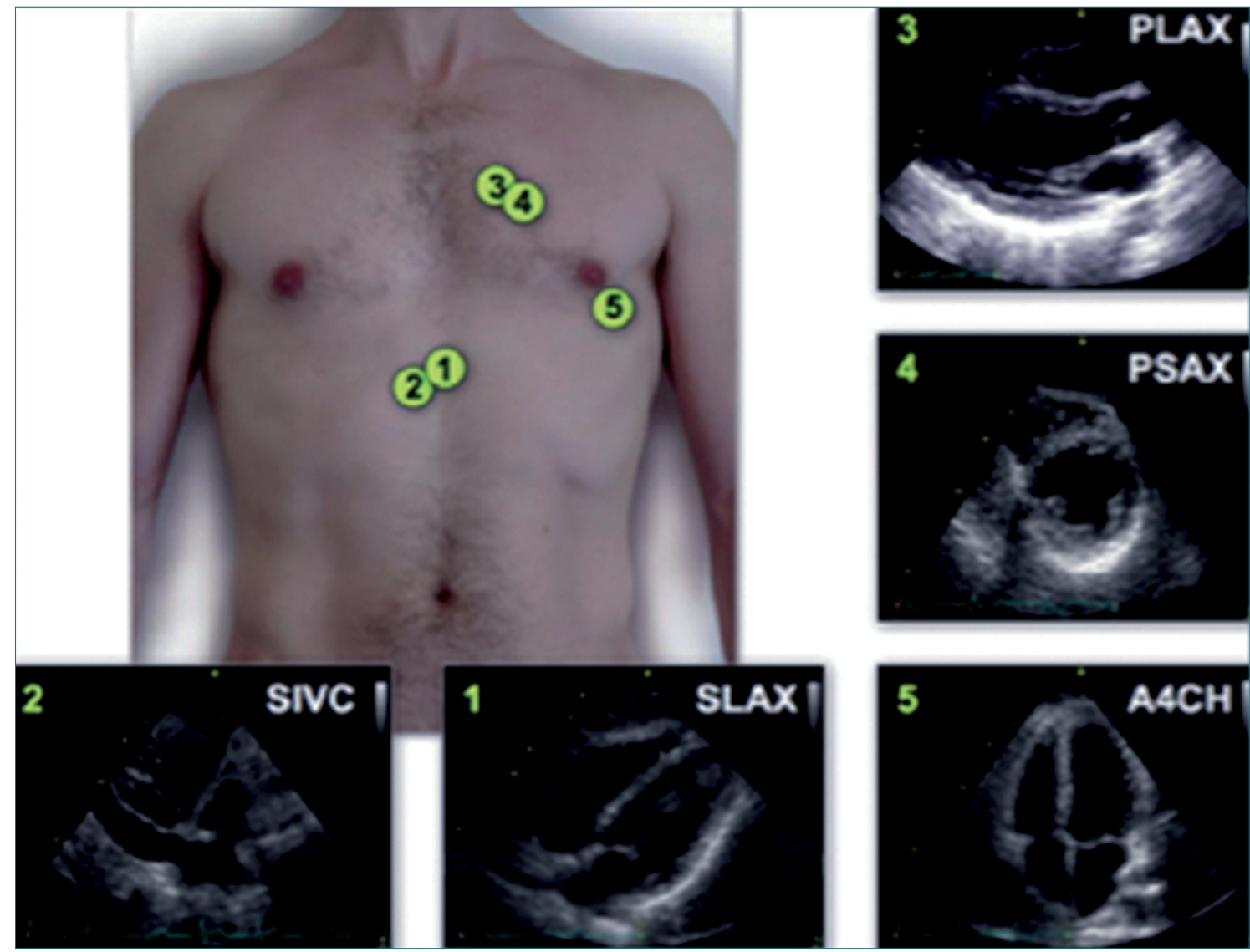

Figura 4. Imágenes estándar de FOCUS: 1) subcostal; 2) vena cava inferior subcostal; 3) paraesternal eje largo, 4) paraesternal eje corto; 5) apical 4 cámaras.

pleural y obstruyen la visibilidad de las líneas A (Figura 6). Corresponden a acumulación de fluido en el intersticio pulmonar. En forma normal pueden verse hasta 3 líneas B por espacio pleural en las zonas de declive del pulmón. Si se visualizan más de 3 en un espacio intercostal, ya sea que se puedan identificar por separado o sean confluentes, dando imagen de pulmón blanco, constituyen una acumulación patológica de líquido instersticial, lo que se conoce como síndrome alveolo-intersticial. Ejemplos de esto son el edema pulmonar y el distrés respiratorio. Como los fluidos se acumulan más en las zonas declives del cuerpo, en el caso de un síndrome alveolo intersticial, las líneas B se hacen más densas en las zonas posteriores del pulmón respecto a las anteriores en un paciente en decúbito supino.

3. Deslizamiento pleural: (lung sliding) corresponde a un artefacto producido por el desplazamiento de la pleura visceral bajo la parietal. Se trata de pequeños puntos o líneas blancas que, a diferencia de las líneas B, recorren solo escasos milímetros bajo la línea de pleura de un modo oscilante y es más notorio mientras más profundos sean los movimientos ventilatorios.

4. Pulso pleural (lung pulse): es un artefacto producido por la vibración transmitida por el latido cardíaco hacia el pulmón, lo que provoca un movimiento breve, rítmico, a nivel de la línea pleural. Es más fácil de ver en modo $\mathrm{M}$ durante un período de apnea.

5. Derrame pleural: inmediatamente bajo la línea de la pleura se observa un espacio anecoico (negro homogéneo) de profundidad variable. Debajo de éste se mueve el pulmón, el cual ahora sí se hará visible, con un parénquima de tamaño disminuido, de densidad tisular aumentada y broncogramas aéreos estáticos (espacios hiperecogénicos 


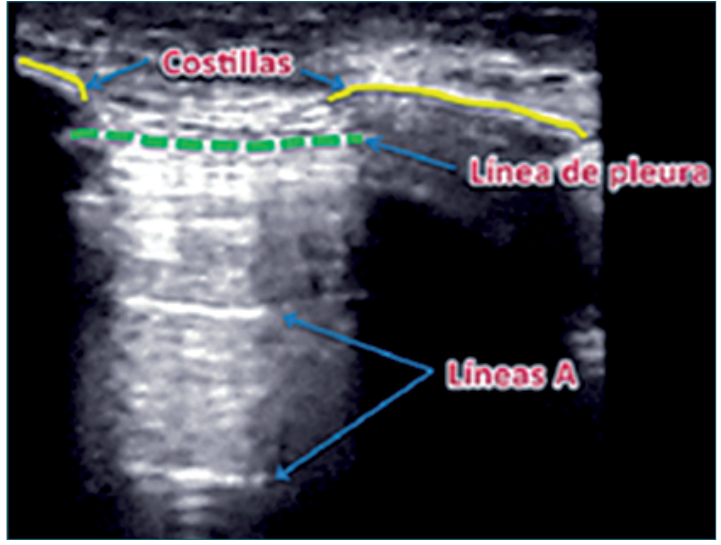

Figura 5. Líneas A.

en el parénquima que no sufren modificaciones con los movimientos respiratorios)[17]. El US permite detectar líquido pleural con volúmenes tan pequeños como 5 a $20 \mathrm{ml}$ en las zonas declives del tórax, en contraste con la radiografía de tórax que requiere al menos 100-150 $\mathrm{ml}$ para ser visualizado[18].

6. Patrón de consolidación: es un modelo de imagen de tejido pulmonar (hepatización) con mínima perdida de tamaño y la presencia de broncograma dinámico.

Cabe hacer notar que existe un artefacto de imagen en espejo, cuyo caso típico es producido por las ondas que chocan sobre el diafragma, que es curvo y muy ecogénico, lo que en algunos casos puede mostrarnos una imagen del hígado en donde debiera haber pulmón. Es muy importante conocer este artefacto ya que no es constante, pero si se ve puede llevar a interpretación errónea de un síndrome de consolidación.

Con estos elementos podemos contestar las siguientes preguntas[19]:

¿Hay neumotórax?: para su diagnóstico hay que considerar diversos hallazgos (Figura 7):

- La presencia de lung sliding, lung pulse y de líneas $\mathrm{B}$ lo descartan en el área examinada.

- La ausencia de lung sliding lo hace sospechar pero, por sí sólo, no confirma el diagnóstico, pues existen otras causas para ello, como son: intubación monobronquial, adherencias pleurales y presencia de bulas.

- Las líneas A pueden observarse en presencia de un neumotórax.

- El punto pleural (lung point) es un signo específi-

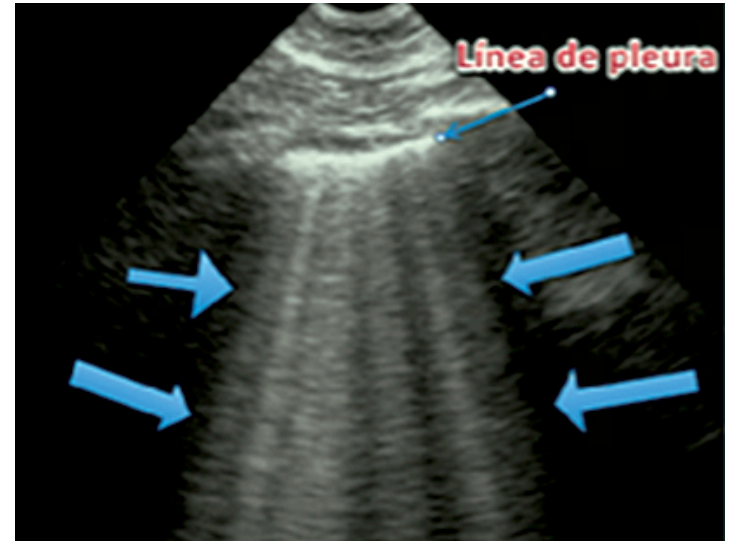

Figura 6. Líneas B (síndrome alveolo-intersticial).

co, no tan fácil de encontrar, pero que confirma el diagnóstico. Consiste en un espacio intercostal en el cual el lung sliding aparece y desaparece en forma intermitente de acuerdo con el movimiento respiratorio.

- Uso de modo M: sobre un espacio intercostal se van a buscar los artefactos producidos por el movimiento (o su ausencia) de la pleura. Hay dos signos fundamentales:

Signo de orilla de playa (sea shore sign): que se produce por el deslizamiento del pulmón con los movimientos respiratorios (semejando granos de arena), en la mitad inferior de la imagen y líneas tipo código de barra en la mitad superior (semejando el mar) (Figura 8).

Signo de la estratósfera: la ausencia de movimiento respiratorio da un aspecto de código de barras en toda la pantalla, signo característico (pero no exclusivo) de neumotórax.

Cabe destacar que la radiografía de tórax tiene sólo $70 \%$ de sensibilidad para la detección del neumotórax en contraste con un valor sobre el $90 \%$ del US[21]. Un metaanálisis de Alrajab y cols., muestra una sensibilidad global de 39,8\% para la radiografía de tórax y de 78,6\% para el US[22]. Por ello, tras realizar una punción venosa central dificultosa, o cuando hay sospecha de que exista barotrauma, el uso del US permite rápidamente diagnosticar un neumotórax sin tener que esperar una radiografía portátil o el traslado a un servicio de rayos.

¿Hay derrame pleural?: si existe, el US permite al operador hacer una estimación aproximada de su volumen en $\mathrm{ml}$, midiendo (en un derrame no tabicado) la distancia intrapleural máxima (en cm) y multipli- 


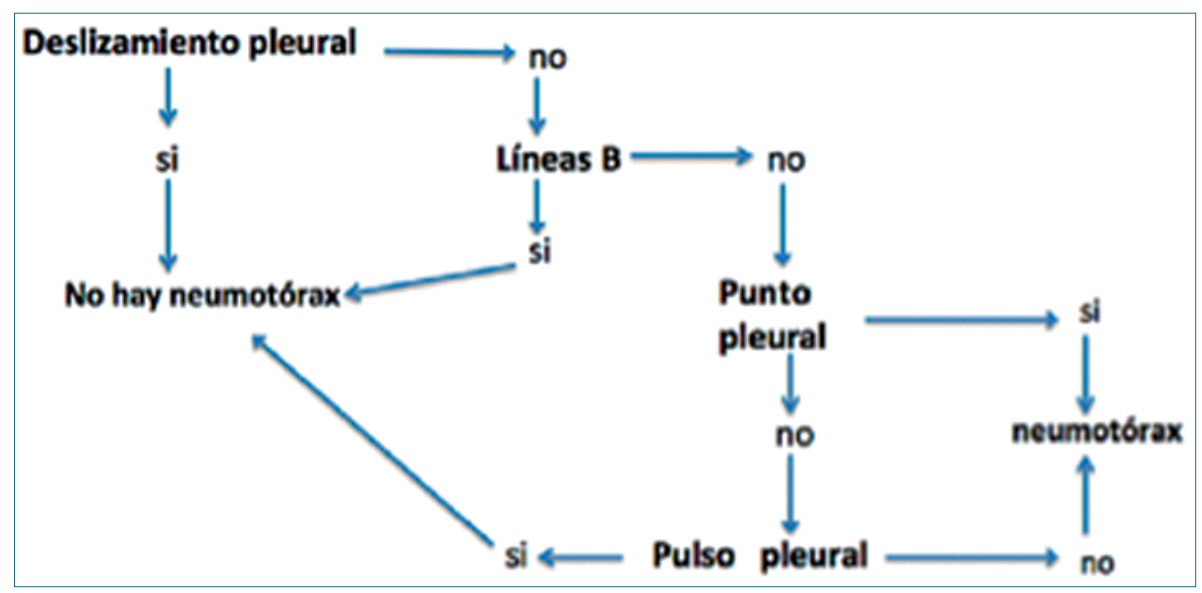

Figura 7. Algoritmo para el diagnóstico de neumotórax[20].
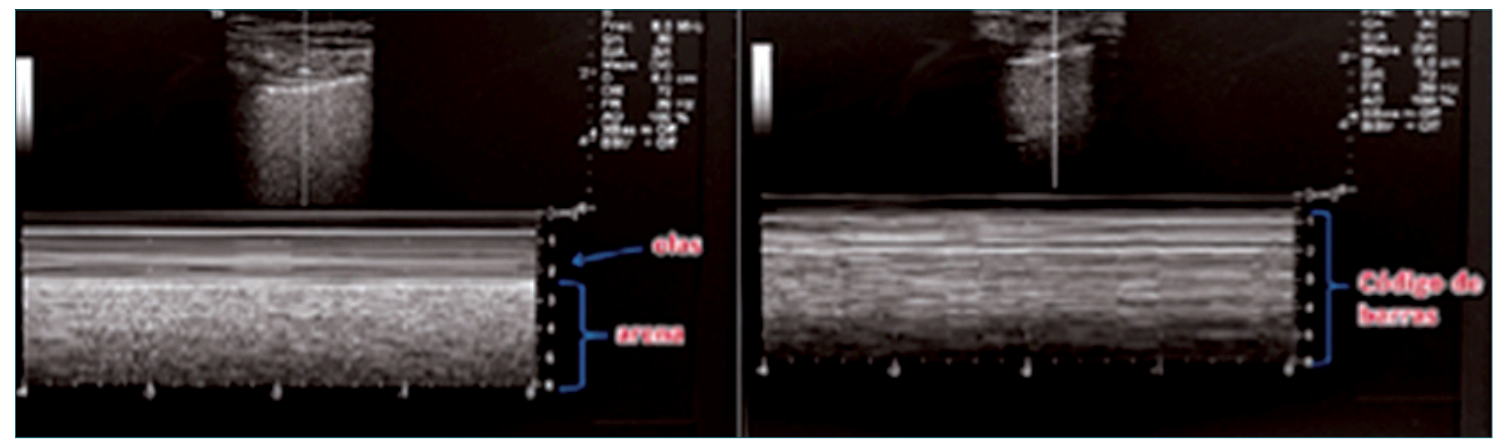

Figura 8. Signo de la orilla de playa (izquierda) y signo del código de barras (derecha).

cándola por $200 \mathrm{ml} \cdot \mathrm{cm}^{-1}[23]$. Asimismo, el US permite mostrar la mejor zona para efectuar un drenaje, minimizando el riesgo de punción pulmonar.

¿Hay atelectasias?: su detección con US es más sensible que con la radiografía de tórax[24] y así permitirá modificar conductas, por ejemplo: kinesioterapia pre y/o posoperatoria, maniobras de reclutamiento durante la ventilación mecánica o modificación de valor de PEEP tanto en el pabellón como en la UCl.

¿Hay síndrome alveolo-intersticial?: el hallazgo de líneas $B$ abundantes o confluentes en distintas zonas pulmonares sirve para restringir los volúmenes infundidos, aportar diuréticos o postergar una extubación hasta que mejoren las condiciones del paciente. Por todo lo anterior, el US en la sala de recuperación es muy útil para el diagnóstico diferencial de disnea posoperatoria. Para los anestesiólogos que trabajan en unidades de cuidado intensivo es de gran utilidad para monitorizar la evolución de la patología pulmonar y determinar el nivel óptimo de PEEP.

\section{US en estómago lleno}

Tiene como objetivo evaluar la calidad y magnitud del contenido gástrico para determinar el riesgo de broncoaspiración[25]. Se realiza con el transductor curvo, aunque también se puede utilizar el transductor lineal en pacientes muy delgados o en niños menores de 8 años. Se aplica el transductor sobre el epigastrio en eje longitudinal del cuerpo (Figura 9), con el marcador apuntando en dirección cefálica, buscando como referencia el lóbulo hepático izquierdo, la aorta o la vena cava inferior, la arteria mesentérica superior y el páncreas. Teniendo estas referencias a la vista (o por lo menos algunas de ellas) se examina el antro gástrico, primero en decúbito dorsal y luego en decúbito lateral derecho, con el objeto de que el contenido que pudiese haber en el fondo gástrico se desplace hacia el antro. Se examina el aspecto del antro gástrico para determinar: si está vacío, si tiene contenido líquido (el que se puede cuantificar) o sóli- 
do, lo que se ve como una mezcla de ecos de distintas densidades que usualmente proyectan una sombra acústica que dificulta o impide la visión de la aorta o la vena cava inferior. Perlas y cols.[26] elaboraron un modelo de regresión lineal en pacientes de diferentes edades en los que se midió mediante US el contenido antral en decúbito dorsal y luego en decúbito lateral derecho (DLD) y, posteriormente, se comparó con el volumen aspirado del estómago por endoscopía. Posteriormente, se realizó la medición ecográfica del área de corte a nivel antral. Estos parámetros se llevaron a una tabla derivada de la fórmula:

Volumen gástrico $=27+14,6$. (Área sección DLD $\left.\mathrm{cm}^{2}\right)-1,28 \cdot$ edad (años)

Según el volumen calculado se determina el riesgo de broncoaspiración ajustado por edad, teniendo como valor de referencia a un volumen menor de 1,5 $\mathrm{ml} \cdot \mathrm{kg}^{-1}$ (que se considera la cantidad de secreción basal) y de alto riesgo cuando es mayor de $1,5 \mathrm{ml} \cdot \mathrm{kg}^{-1}$ (Tabla 1 y Figuras 10 y 11).

Spencer y cols.[27], han desarrollado otro modelo de regresión en población pediátrica siguiendo una metodología similar, con bastante buena correlación entre lo medido por US y el contenido aspirado durante el examen endoscópico. La fórmula en este caso se basa en la edad en meses:

Volumen gástrico $=-7,8+3,5$. (Área sección DLD $\left.\mathrm{cm}^{2}\right)+0,127 \cdot$ edad (meses)

Puede ser de gran utilidad cuando no se tiene clara la data del ayuno o en un paciente incapaz de dar información confiable. Por otra parte, se dan casos en que el ayuno no está cumplido a cabalidad, pero al comprobar por US que el estómago está vacío, se podría proceder con una cirugía electiva. El efecto del ayuno es muy variable en cada paciente. Se estima que se requiere realizar 33 evaluaciones para obtener un mínimo de pericia.

Limitantes: el US de estómago no es adecuado para pacientes con anatomía alterada como gastrectomía previa o bypass, banda gástrica in situ, gran hernia hiatal o fundoplicatura previa.

\section{FAST extendido (E-Fast)}

Es un examen realizado principalmente por urgenciólogos en pacientes con trauma toracoabdominal[28]. Va dirigidamente a buscar hemoperitoneo, hemotórax, neumotórax y derrame pericárdico con o sin taponamiento cardíaco. Se realiza habitualmente con transductor curvo de baja frecuencia en 4 ventanas abdominales y 2 torácicas:

Ventana hepatorrenal: (Figura 12) en la línea axilar media derecha, iniciando el examen aproximadamente a la altura de la octava costilla, con el transductor en el eje longitudinal del cuerpo y el marcador en dirección cefálica, deslizándolo desde arriba hacia abajo y viceversa. Se busca visualizar la cortina pulmonar (que corresponde al movimiento respiratorio del artefacto del pulmón que en condiciones normales cubre y descubre el hígado a modo de cortina), diafragma, hígado, riñón derecho y el espacio hepatorrenal (espacio de Morrison), que es el lugar donde se va a centrar nuestra atención. El hallazgo de líquido (imagen hipoecoica) entre el hígado y el riñón permite detectar líquido libre peritoneal, que en el contexto de un trauma abdominal será interpretado como hemoperitoneo. Para que éste sea visible deben acumularse al menos $500 \mathrm{ml}$ de sangre en la cavidad peritoneal. Se puede aumentar la sensibilidad al posicionar al paciente en Trendelenburg, con lo que $350 \mathrm{ml}$ de fluido podrían dar un examen positivo. Esta misma ventana se usa para detectar un hemotórax, observando por encima de la línea diafragmática. Igualmente puede detectarse contenido líquido entre el diafragma y el hígado.

- Ventana esplenorrenal: (Figura 13) El examen se

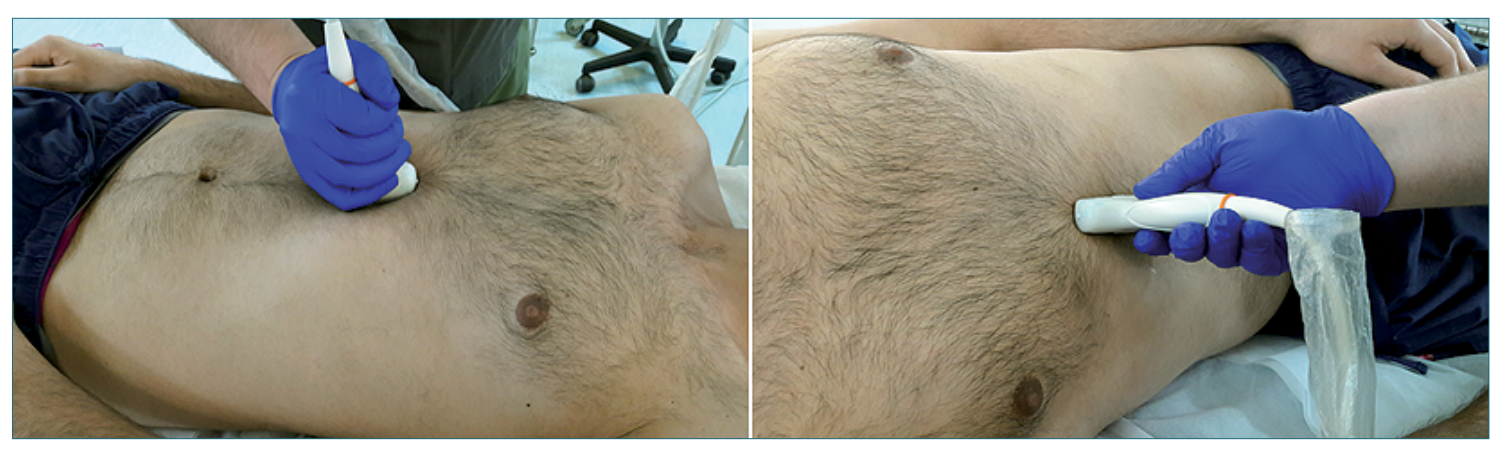

Figura 9. Ultrasonido gástrico en decúbito dorsal y luego decúbito lateral derecho. 


\begin{tabular}{|c|c|c|c|c|c|c|c|}
\hline \multirow{2}{*}{$\begin{array}{l}\text { A.S.T. en } \\
\text { DLD }\left(\mathrm{cm}^{2}\right)\end{array}$} & \multicolumn{7}{|c|}{ Edad (años) } \\
\hline & 20 & 30 & 40 & 50 & 60 & 70 & 80 \\
\hline 3 & 45 & 32 & 20 & 7 & 0 & 0 & 0 \\
\hline 5 & 74 & 62 & 49 & 36 & 23 & 10 & 0 \\
\hline 7 & 103 & 91 & 78 & 65 & 52 & 40 & 27 \\
\hline 9 & 133 & 120 & 107 & 94 & 82 & 69 & 56 \\
\hline 11 & 162 & 149 & 136 & 123 & 111 & 98 & 85 \\
\hline 13 & 191 & 178 & 165 & 153 & 140 & 127 & 114 \\
\hline 15 & 220 & 207 & 194 & 182 & 169 & 156 & 143 \\
\hline 17 & 249 & 236 & 224 & 211 & 198 & 185 & 173 \\
\hline 19 & 278 & 266 & 253 & 240 & 227 & 214 & 202 \\
\hline 21 & 307 & 295 & 282 & 269 & 256 & 244 & 231 \\
\hline 23 & 337 & 324 & 311 & 298 & 285 & 273 & 260 \\
\hline 25 & 366 & 353 & 340 & 327 & 315 & 302 & 289 \\
\hline 27 & 395 & 382 & 369 & 357 & 344 & 331 & 318 \\
\hline 29 & 424 & 411 & 398 & 386 & 373 & 360 & 347 \\
\hline
\end{tabular}

A.S.T. en DCL: Área de sección transversal en décubito lateral derecho.

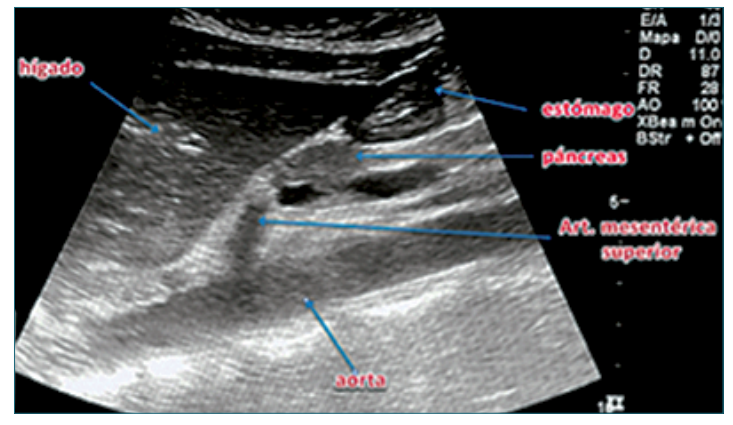

Figura 10. Estómago vacío.

realiza en la misma ubicación en posición contralateral, a la altura de la octava costilla con el marcador orientado a cefálico, pero a nivel de la línea axilar posterior (los nudillos del operador pegados a la cama), identificando nuevamente la cortina pleural, diafragma, bazo y riñón izquierdo. Los elementos que se buscan son similares que, al lado derecho, identificando en este caso el espacio esplenorrenal.

- Ventana subxifoídea: (Figura 14) se coloca el transductor en forma transversal, prácticamente

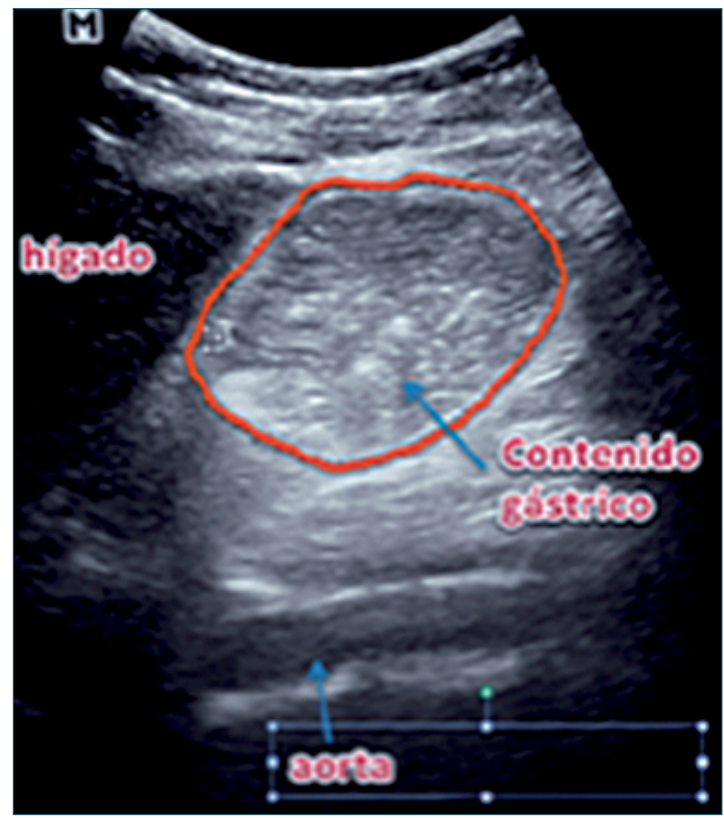

Figura 11. Estómago lleno. 
acostado sobre el abdomen del paciente, apuntando hacia el corazón. Permite principalmente la detección de derrame pericárdico, pero también se puede apreciar la contractilidad cardíaca, el llene de las cámaras y, en el caso de reanimación cardiopulmonar, verificar si hay contracción cardiaca o se está ante una asistolia o fibrilación ventricular.

- Ventana suprapúbica: (Figura 15) se realiza en 2 planos, longitudinal y transversal. Se busca identificar la indemnidad (o rotura) de la vejiga y la presencia de líquido libre entre las asas intestinales. En este caso el líquido, al ser extraluminal, se aprecia en colecciones terminadas en puntas (estrelladas), lo que es determinado por la confluencia redondeada del intestino adyacente.

- Ventanas pulmonares: (Figura 16) se instala el transductor entre el segundo y tercer espacio intercostal, a nivel de la línea medioclavicular en busca de deslizamiento pleural. Se usa esta localización porque el aire, al ser más liviano, se dirige hacia esta ubicación cuando el paciente está en decúbito supino, en caso de neumotórax. El procedimiento debe realizarse en ambos hemotórax.

Este examen permite vigilar la evolución del paciente traumatizado, especialmente de aquellos hemodinámicamente inestables. Un examen E-Fast inicialmente negativo en la urgencia puede hacerse positivo al ingresar a pabellón o a la Unidad de Cuidados Intensivos. Esto permitiría tratar una condición no detectada en un principio, por ejemplo, un neumotórax, que podría ser manejado con un drenaje pleural antes de inducir una anestesia general, evitando así la transformación a un neumotórax a tensión.

Otra situación donde este examen podría ser muy útil es en la unidad de recuperación. Un paciente que se torna hemodinámicamente inestable tras una cirugía abdominal pudiera, entre otras posibilidades, tener un sangrado peritoneal, lo que es detectable por este método sin tener que trasladar al paciente a unidad de radiología para su diagnóstico.

\section{US en resucitación}

Enfatizando lo accesible del US como examen a la cabecera del paciente y aunando algunas de las evaluaciones ya revisadas en este artículo, es posible también orientar la resucitación mediante fluidos de pacientes en shock, en base a elementos clave para evitar una volemización insuficiente o excesiva. Así, considerando elementos del examen ultrasonográfico pulmonar que nos orientan a presencia o ausencia de

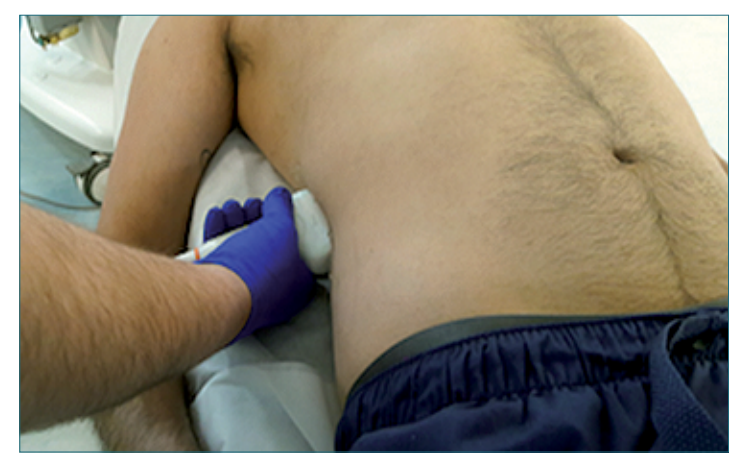

Figura 12. Ventana hepato-renal.

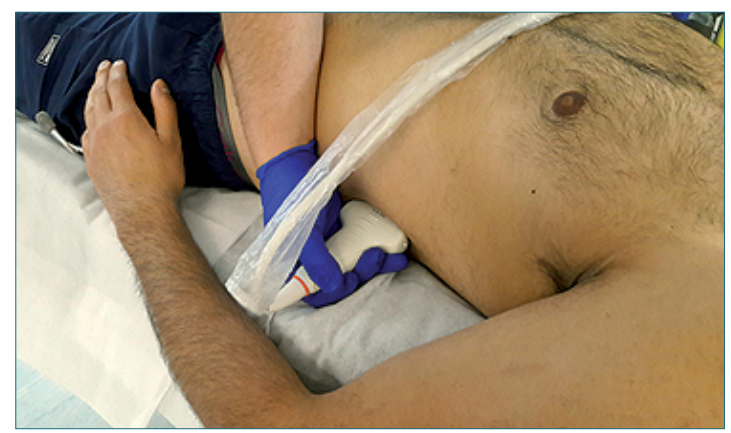

Figura 13. Ventana esplenorenal.

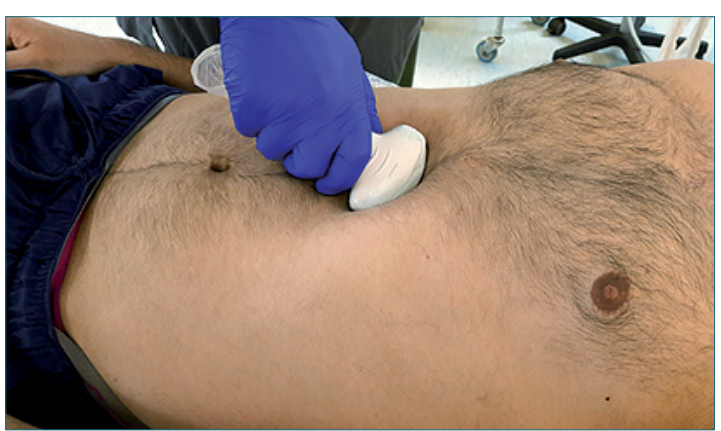

Figura 14. Ventana subxifoídea.

congestión pulmonar y de la vena cava inferior relacionados con su diámetro y respuesta a los cambios hemodinámicos propios de la ventilación[29], podemos integrar variables para definir conducta. Lee y cols., han desarrollado precisos protocolos sobre este tema[30] (Figura 17).

- Examen ultrasonográfico de la vena cava inferior (VCI): su diámetro y la variación de éste durante el ciclo ventilatorio dependen, al igual que otros indicadores dinámicos de respuesta a volumen, de 


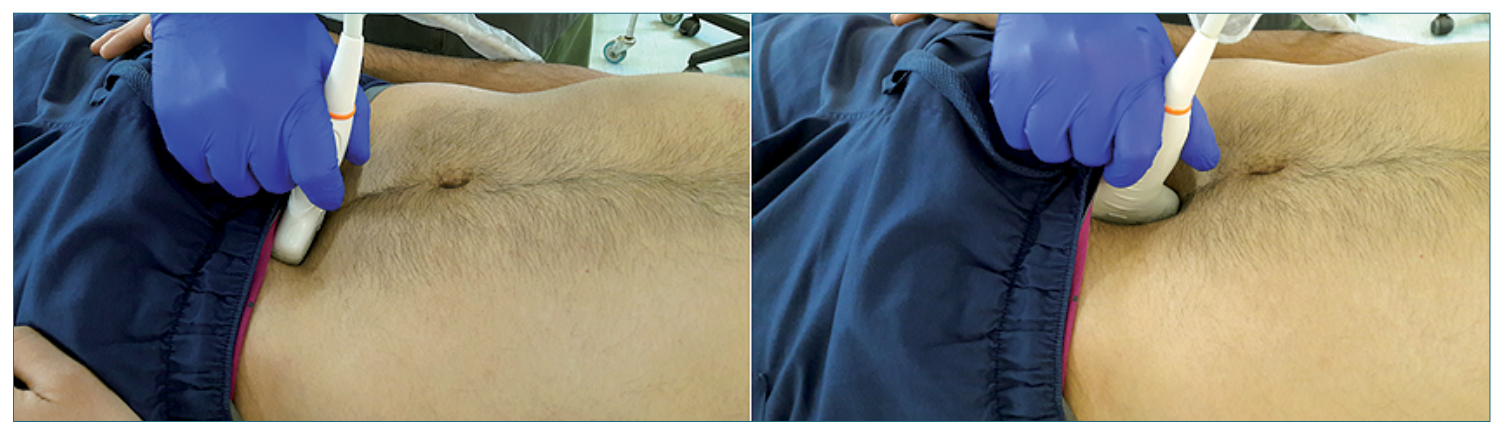

Figura 15. Ventana suprapúbica en 2 planos perpendiculares.

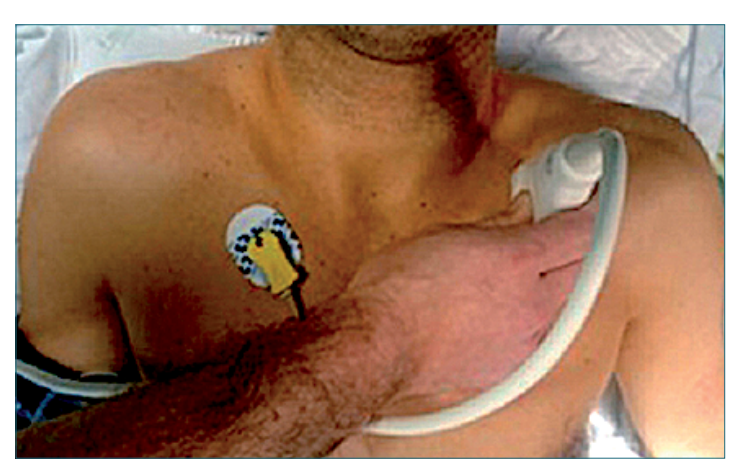

Figura 16. Ventana pulmonar. Se realiza a ambos lados.

la modalidad ventilatoria de cada paciente. Básicamente, si se encuentra en ventilación mecánica invasiva o no y si ésta es sincrónica al ventilador en el caso de la primera opción. Sólo bajo ventilación mecánica invasiva sincrónica al ventilador, se puede obtener mediciones confiables de los cambios dinámicos de la VCI.

Sobre esto se han desarrollado clasificaciones, como el "índice de distensibilidad de la vena cava inferior" (dIVC)[31], que corresponde al diámetro de la $\mathrm{VCl}$ al final de la inspiración (Dmáx), menos el diámetro de la $\mathrm{VCl}$ al fin de la espiración (Dmín), dividido por el diámetro de $\mathrm{VCl}$ al final de la espiración (Dmín), expresado en porcentaje, parámetros que se pueden medir con US usando una ventana subcostal. Los estudios sugieren que un valor mayor a 18\% constituye una respuesta a volumen positiva, con $90 \%$ de sensibilidad y especificidad.

Índice de distensibilidad de la VCI (dIVC) = Dmáx Dmín/Dmín x 100

Otro índice definido es la "variación respirato- ria del diámetro de la vena cava inferior" ( $\triangle$ DIVC), donde un valor de $12 \%$ discrimina entre respondedores y no respondedores con VPP de $93 \%$ y VPN de $92 \%[32]$.

Variación respiratoria del diámetro de la $(\Delta \mathrm{DIVC})=$ (Dmáx - Dmín) / [(Dmáx+ Dmín)/2]

Las mediciones anteriores, sin embargo, excluyen a pacientes no sometidos a VMI sincrónica, para los cuales, pueden resultar útiles otros indicadores tales como el "diámetro máximo de la vena cava inferior" (D máximo). Éste, tendría poder discriminatorio para diferenciar a los pacientes hipovolémicos en su valor inferior. Así, un valor de D máximo de la VCI menor a $1,5 \mathrm{~cm}$ tendría suficiente sensibilidad y especificidad para identificar a aquellos pacientes que responderán a volumen. Por otro lado, un gran diámetro de $\mathrm{VCl}$, definido por Lee y cols., como mayor a $2,5 \mathrm{~cm}$, puede ser consistente con un estado de sobrecarga de volumen, en que es poco probable el aumento del gasto cardiaco en respuesta a un mayor aporte de fluidos. Debe tenerse presente que los D máximo grandes y no variables no son específicos para estados de sobrecarga de volumen y, esta distinción, solo se puede hacer en el contexto clínico correcto.

- Examen ultrasonográfico pulmonar: puede aportar información valiosa frente a la dificultad de información predictiva de la VCI en algunos pacientes. Así, se ha evidenciado que éste puede mostrar de forma rápida y minuciosa el edema pulmonar temprano que se desarrolla cuando el paciente es sobrerresucitado con volumen. Para evaluar lo anterior se usan dos artefactos ya mencionados del ultrasonido pulmonar: las líneas A y las líneas B. La predominancia de líneas A indica septo interlobular seco y presión de aurícula izquierda baja lo normal, mientras que la predominancia de líneas B indica síndrome alveolointersticial, signo consis- 


\section{RESUCITACIÓN BASADA EN ULTRASONOGRAFÍA PULMONAR Y VENA CAVA INFERIOR}

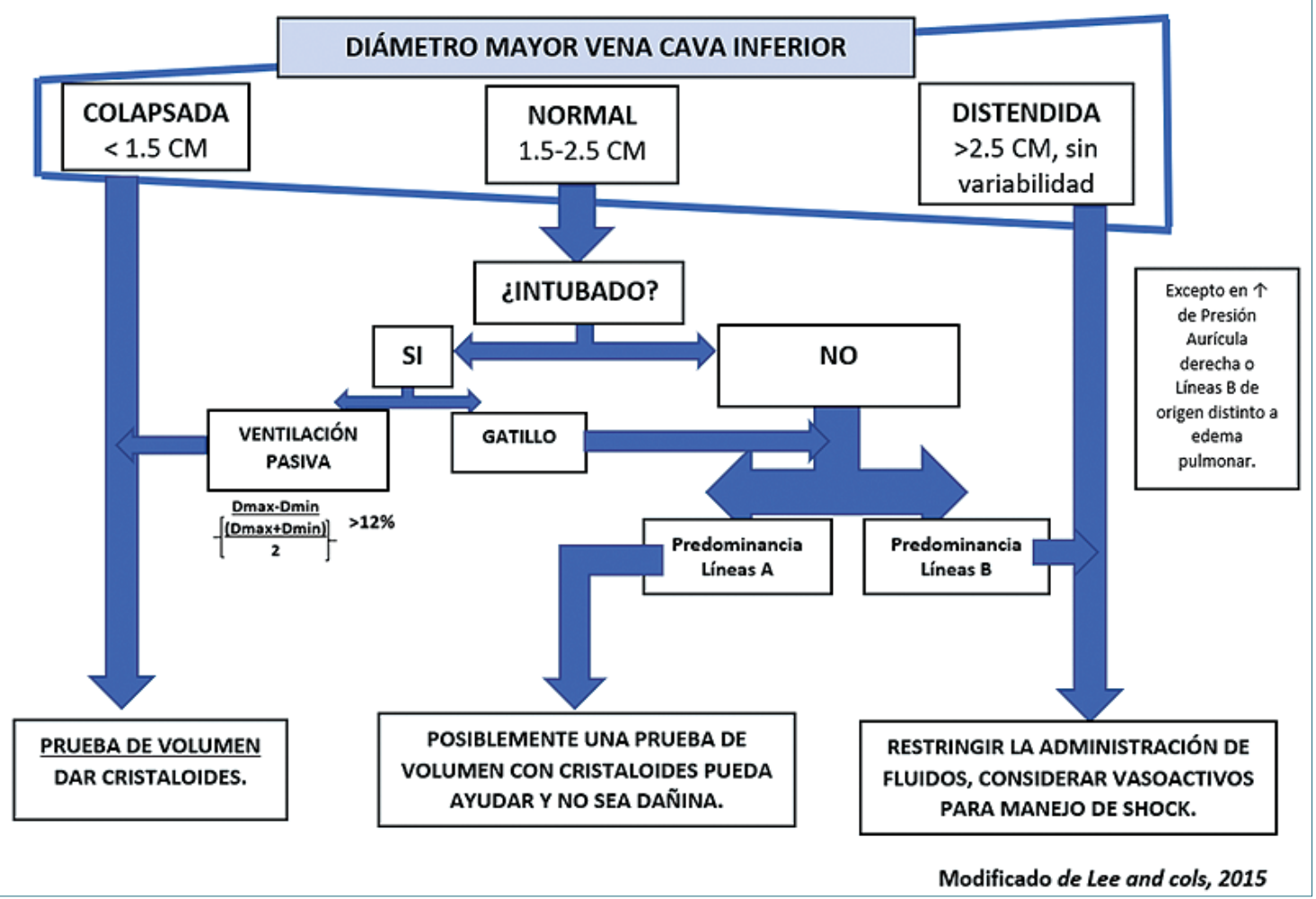

Figura 17. Esquema sobre la utilización de ultrasonografía de vena cava inferior y pulmonar en la resucitación con volumen.

tente de edema pulmonar a menudo preclínico y prerradiográfico.

\section{US en vía aérea (VA)}

Kristensen y cols.[33], estudiaron el uso de US para evaluación de la VA. Ellos demostraron que es posible visualizar imágenes desde la base de la lengua hasta los anillos traqueales, permitiendo así identificar las diferentes estructuras, el funcionamiento de las cuerdas vocales y las estructuras anatómicas adyacentes a la VA. En este contexto cabe destacar la correcta identificación de la membrana cricotiroídea como paso previo al manejo de la VA difícil, en donde una cricotirotomía pudiera constituir un acceso de salvataje. Esta estructura puede ser difícil de identificar, especialmente en cuellos edematosos, desviaciones de la tráquea por compresión tumoral, abscesos, secuelas de radioterapia, quemaduras o columna cervical inestable.

Se usa el transductor lineal, apoyándolo en forma transversal sobre la escotadura esternal para identificar los anillos traqueales, buscando la línea media y luego se rota en $90^{\circ}$, ascendiendo por el cuello, reconociendo los cartílagos traqueales que muestran una configuración semejante a "cuentas de rosario", apareciendo luego el cartílago cricoides con características sonográficas similares a los cartílagos traqueales, pero de mayor tamaño y de ubicación más anterior. Siguiendo en dirección cefálica aparece la membrana cricotiroidea[33] (Figura 18). Al identificar la membrana se aconseja dejar una marca sobre la piel y así, en caso de emergencia, se evita perder un tiempo precioso en identificarla.

El transductor puesto en forma transversal sobre la laringe permite ver el movimiento de las cuerdas vocales. Se le pide al paciente que respire tranquilamente y luego que vocalice "aaaaaaa". Si esta maniobra se realiza antes y después de una tiroidectomía podría demostrar una parálisis unilateral o bilateral de cuerdas vocales por lesión del nervio laríngeo, lo que es menos invasivo que hacer una laringoscopía 
posoperatoria en el paciente ya extubado.

El uso de US en la VA también sirve para confirmar la correcta intubación de la tráquea en forma directa e indirecta[34]. La indirecta, es comprobando el lung sliding bilateral tras la intubación. La directa, se hace con el transductor puesto en forma transversal a los anillos traqueales. Si no hay cambios detectados en la anatomía al intubar se considera que el tubo se encuentra en tráquea (como ésta contiene aire no deja ver el tubo en su interior). Si la intubación es esofágica, se verá la aparición de un segundo lumen al lado y un poco más atrás de la tráquea, lo que se conoce como signo del ganso (goose sign) (Figura 19). Para poder verlo es necesario hacer esta observación en tiempo real, porque si se realiza después de la intubación esofágica, el reconocimiento es más difícil y la sensibilidad diagnóstica disminuye en forma ostensible. Este reconocimiento en forma oportuna permite evitar la insuflación del estómago, lo que aumenta el riesgo de broncoaspiración. Desde luego, este método de detección de una intubación esofágica toma tiempo y requiere experiencia, por lo que en caso alguno reemplaza la detección de curva capnográfica como signo patognomónico de intubación traqueal.

Ramsingh y cols.[35], demostraron que el US es superior a la auscultación en determinar la correcta localización del tubo endotraqueal (si es traqueal, monobronquial derecha o izquierda). En este estudio, 42 pacientes sometidos a anestesia general fueron intubados por un operador que, mediante fibrobroncoscopía y previa asignación aleatoria, intubó la tráquea, bronquio izquierdo o bronquio derecho. A continuación, un segundo anestesista, ciego a la asignación de los casos, auscultó y anotó el tipo de intubación encontrado (traqueal, bronquial derecha o izquierda). Luego un tercer anestesista, también ciego, usó US y anotó el tipo de intubación. La identificación correcta de la intubación traqueal versus intubación bronquial fue de $62 \%$ para el grupo auscultación y 95\% para el grupo US. Teniendo en cuenta este hecho, el US ayuda a identificar la adecuada ubicación de un tubo doble lumen, especialmente cuando no se cuenta con fibrobroncoscopio (que constituye el estándar de oro para la comprobación de su correcta instalación) ya que permite ver el lung sliding cuando hay una ventilación adecuada y la desaparición de éste cuando se ocluye la rama correspondiente al pulmón que se desea bajar.

La técnica tiene algunas limitaciones: la presencia de un collar cervical impide la observación de la VA alta (a menos que se pueda remover), patología

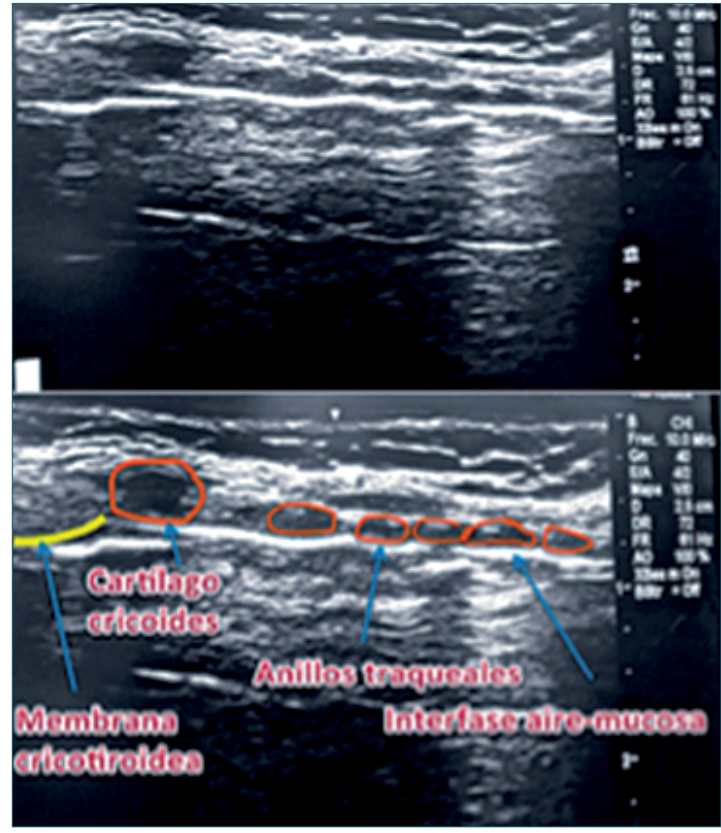

Figura 18. Anillos traqueales y cartílago cricoides.
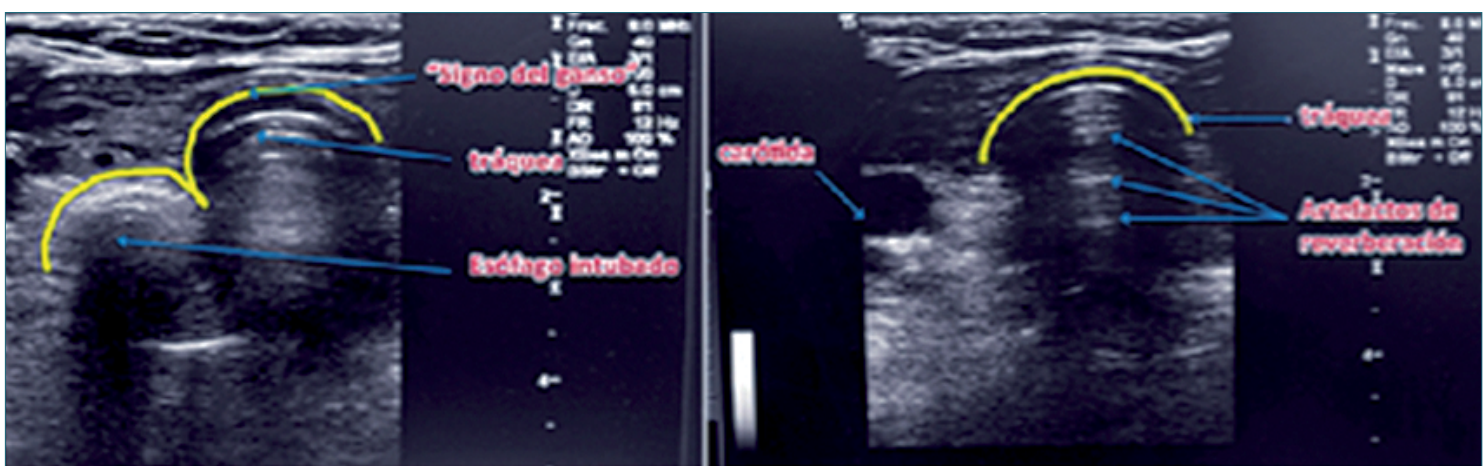

Figura 19. Intubación esofágica con signo del ganso (izquierda) y traqueal (derecha). 
pulmonar que impida ver el lung sliding (neumonía, consolidación pulmonar, adherencias pleurales) y presencia de enfisema subcutáneo que impida la visión ecográfica. Esto último se aplica para cualquier ventana ecográfica, no solamente de la vía aérea.

Algunos otros usos del US en la VA son los siguientes:

- Bloqueos nerviosos relacionados a VA, especialmente el bloqueo del nervio laríngeo superior[36],[37].

- Para decidir el tamaño correcto del tubo endotraqueal, cánulas de traqueotomía y tubos de doble lumen. Respecto a esto último, Brodsky ha correlacionado el diámetro traqueal medido radiológicamente a nivel clavicular[38] y luego por TAC de tórax[39], estableciéndose una predicción del tamaño adecuado del tubo de doble lumen respecto a la medición obtenida del diámetro externo de la tráquea por US:

$\geq 18 \mathrm{~mm}$ : $41 \mathrm{Fr}$ (tubo doble lumen izquierdo o derecho).

$\geq 16 \mathrm{~mm}: 39 \mathrm{Fr}$

$\geq 15 \mathrm{~mm}: 37 \mathrm{Fr}$

$\geq 14 \mathrm{~mm}: 35 \mathrm{Fr}$

- Como guía para realizar una traqueostomía percutánea en pacientes de UCI[40]. Rajajee y cols. efectuaron 13 traqueostomía en pacientes obesos mórbidos con esta técnica. Se retiró el tubo endotraqueal y se introdujo un fibrobroncoscopio a la vía aérea. La tráquea se puncionó bajo visión ecográfica en tiempo real, mirando el avance de la guía metálica dentro de la tráquea para ir chequeando al mismo tiempo la posible aparición de complicaciones. Se midió con ecografía la profundidad de los anillos traqueales y se visualizó los vasos anteriores a la tráquea con doppler color para evitar puncionarlos. Se verificó el sitio adecuado de punción entre el primer y quinto anillo traqueal, elementos que son difíciles de evaluar usando solamente la técnica de palpación.

\section{US en nervio óptico}

Se ha propuesto la medición del diámetro de la vaina del nervio óptico como un método de evaluación no invasiva y precoz de hipertensión intracraneana. Consiste en el uso de un transductor lineal de alta frecuencia, puesto sobre el globo ocular, previamente protegido con un parche adhesivo transparente sobre el que se esparce abundante gel (Figura 20). El nervio óptico se identifica como una estructura hipoecoica de trayecto regular en la parte posterior al globo ocular y, como está rodeado por la duramadre, un aumento de la presión intracraneana, se transmite a través del espacio subaracnoídeo hacia su vaina, aumentando su diámetro[41]. El estándar de medición del diámetro del nervio óptico requiere trazar una línea de referencia que se inicia por convención a 3 mm de la unión del nervio óptico con el globo ocular. En general se usa como valor normal un punto de corte de $5 \mathrm{~mm}$. Sin embargo, otros estudios no han concordado con este valor, sugiriendo números que oscilan entre 5 y 5,9 mm. Este examen ayudaría a decidir el traslado del paciente afectado a un centro neuroquirúrgico[34].

\section{Protocolos ecográficos en contexto de urgencias y perioperatorio}

El ultrasonido se ha vuelto una herramienta útil y de fácil acceso en la medida que su calidad, portabilidad y disponibilidad han mejorado con el paso del tiempo, lo que se ha sumado a la valiosa información que entrega y la posibilidad de ser usado por médicos no especialistas. De este modo, anestesiólogos, urgenciólogos e intensivistas, entrenados en aplicación de protocolos sencillos y validados, hacen que esta técnica sea idónea para usar a la cabecera del paciente en situaciones tiempo dependientes. En la literatura existen muchos términos que se refieren a estos exámenes ecográficos acotados como lo son hand-held, point-of-care, bedside, quick-look cardiac ultrasound, o ultrasound stethoscope. Por otra parte, existen muchas siglas con las que se denominan los diferentes protocolos creados en este contexto, entre los que encontramos los protocolos FAST, FATE, FOCUS, FEEL, RUSH, ACCES, BLUE, FALL, etc., correspondiente al acrónimo de las iniciales de su nombre en inglés. Estos protocolos varían según la situación clínica objetivo en que se aplican, los sistemas evaluados y las visiones buscadas.

En la Tabla 2 se resumen los protocolos más re-

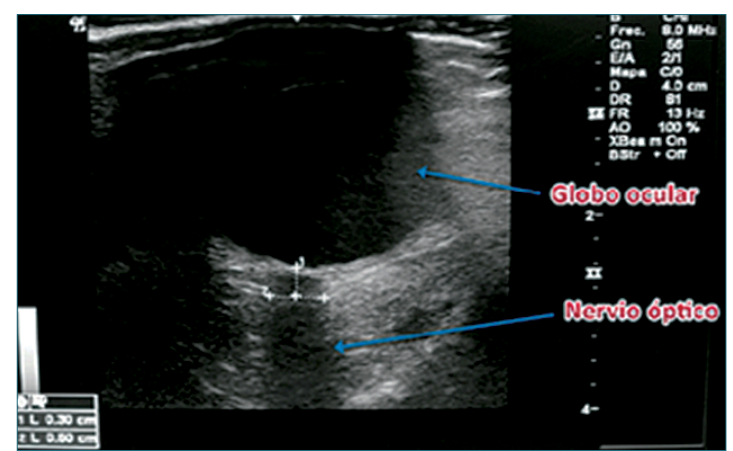

Figura 20. US del nervio óptico. 
levantes en el contexto perioperatorio de urgencias. Después, se describe brevemente por separado la utilidad de algunos de estos protocolos. PLAX: eje largo paraesternal, PSAX: eje corto paraesternal, A4CH: 4 cámaras apical, SIVC: visión subcostal vena cava inferior, CSD: cuadrante superior derecho, CSI: cuadrante superior izquierdo, ECAA: eje corto aorta abdominal, Puntos BLUE y PLAPS: ver texto más adelante.

FOCUS: según definición de la Sociedad Americana de Ecocardiografía, es un examen focalizado del sistema cardiovascular realizado por un médico usando ultrasonografía como un adjunto al examen físico, para reconocer signos específicos ultrasonográficos que representan una estrecha lista de diagnósticos potenciales en contextos clínicos específicos. Se usa como apoyo cuando el paciente tiene síntomas sugerentes de anormalidad del sistema cardiovascular. No realiza mediciones cuantitativas. Se basa en las modalidades 2D y doppler color.

FAST: la evaluación ultrasonográfica realizada como parte inicial del examen y resucitación del paciente de trauma es conocida en inglés como Focused Assessment with Sonography for Trauma (evaluación focalizada con ultrasonografía para trauma), utilizando el acrónimo FAST. Al adicionar visiones para evaluar neumotórax se habla de FAST extendido o EFAST. Detecta fluido intraperitoneal mayor a $200 \mathrm{ml}$. No es útil para lesiones retroperitoneales.

RUSH: del inglés Rapid ultrasound in shock (ultrasonido rápido en shock) es usado en pacientes con hipotensión de causa desconocida. Se examina primero el corazón (la bomba): el examen se centra en las cuatro ventanas cardiacas. En segundo lugar, la volemia (el estanque): a través de la ventana subxifoídea, en ejes longitudinal y transverso de la $\mathrm{VCl}$; y finalmente, las arterias y venas (las cañerías): mediante el examen ecográfico de las grandes arterias y venas del organismo.

ACES: utilizado en pacientes con hipotensión indiferenciada en pacientes no traumáticos. Acrónimo del inglés Abdominal and Cardiac Evaluation with Sonography in Shock (evaluación abdominal y cardíaca con ultrasonografía en estado de shock). Utiliza 6 visiones básicas, mediante las cuales busca definir si el tipo de shock es obstructivo, séptico, cardiogénico o hipovolémico.

FATE: la sigla corresponde a Focus Assessed Transthoracic Echocardiography (ecocardiografía transtorácica dirigida), utiliza ventanas cardiacas y pleurales para evaluar la causa de la inestabilidad hemodinámica; principalmente tamaño de cámaras, grosor de paredes cardiacas, función ventricular y pleuras.

BLUE: sus siglas se refieren a Bedside Lung UItrasound in Emergency (ecografía pulmonar al lado de la cama del paciente en emergencia). Es un protocolo rápido de menos de 3 minutos que auxilia en el diagnóstico de insuficiencia respiratoria aguda, para orientación diagnóstica. Se basa en ecografía pulmonar e incluye análisis venosos en casos apropiados. Mediante su algoritmo se busca perfiles compatibles con edema pulmonar, embolismo pulmonar, neumonía, EPOC, asma y neumotórax. Utiliza puntos específicos de exploración que se establecen tras poner ambas manos sobre el hemitórax del paciente, una inmediatamente bajo la clavícula y la otra inmediatamente adyacente a la anterior excluyéndose los pulgares de modo que contacten entre si ambos dedos índices, así el punto BLUE superior queda al centro de la mano superior y el punto BLUE inferior se ubica al centro de la palma de la mano inferior. El punto PLAPS se define por la intersección de una línea horizontal que nace del punto BLUE inferior y la línea axilar posterior.

FALL: acrónimo de Fluid Administration Limited by Lung Sonography (Administración de Fluidos Guiada por Ultrasonografía Pulmonar), es derivado del protocolo BLUE. Busca presencia o ausencia de signos de congestión pulmonar observando la evolución de las modificaciones de las líneas $B$, indicadoras de edema pulmonar.

FEEL: sigla de "Focused Echocardiographic Evaluation in Life Support" (Ecocardiografía Dirigida a la Evaluación del Soporte Vital). Se utiliza como apoyo en busca de causas de paro cardiorrespiratorio, en la rama de pacientes no desfibrilable: actividad eléctrica sin pulso o asistolia. Se centra dirigidamente en diagnóstico o descarte de taponamiento cardiaco, neumotórax a tensión, hipovolemia, tromboembolismo pulmonar, etc. Es realizado por un operador que no participa en otras labores de reanimación y que debe utilizar el espacio de tiempo en que se chequea ritmo y pulso para efectuar el examen ultrasonográfico, sin demorar la resucitación cardiopulmonar. Habitualmente se graba el ultrasonido para su interpretación posterior.

En la Figura 21 se esquematizan las principales ventanas mediante las cuales se obtienen las visiones de los protocolos mencionados. 


\section{Tabla 2. Protocolos más relevantes en el contexto perioperatorio de urgencias}

\begin{tabular}{|c|c|c|c|c|}
\hline Protocolo & $\begin{array}{l}\text { Modalidades y } \\
\text { visiones }\end{array}$ & Contextos clínicos & Alcances & Desventajas \\
\hline FOCUS & $\begin{array}{l}\text { Modalidades } \\
\text { - 2-D } \\
\text { - Doppler color } \\
\text { Visiones } \\
\text { PLAX, PSAX, } \\
\text { A4CH, S4CH, } \\
\text { SIVC }\end{array}$ & $\begin{array}{l}\text { Paciente con anomalías del } \\
\text { sistema cardiovascular }\end{array}$ & $\begin{array}{l}\text { - Función sistólica y dimensión ventricular } \\
\text { - Estado de volemia y respuesta a volumen } 3 \text { Tapo- } \\
\text { namiento o derrame pericárdico } \\
\text { - Anomalías anatómicas gruesas } \\
\text { - Signos gruesos de patología cardiaca crónica }\end{array}$ & $\begin{array}{l}\text { - Operador depen- } \\
\text { diente } \\
\text { - Información no } \\
\text { cuantificable }\end{array}$ \\
\hline E-FAST & $\begin{array}{l}\text { Modalidades } \\
\text { - 2-D } \\
\text { - Modo M } \\
\text { Visiones S4CH, } \\
\text { CSD, CSI, Pelvis, } \\
\text { tórax anterior }\end{array}$ & $\begin{array}{l}\text { Paciente con trauma de tórax } \\
\text { y/o abdomen }\end{array}$ & $\begin{array}{l}\text { - Identifica fluido intraperitoneal, pericárdico y pleu- } \\
\text { ral }\end{array}$ & $\begin{array}{l}\text { - Operador depen- } \\
\text { diente } \\
\text { - Sensibilidad limi- } \\
\text { tada para descar- } \\
\text { tar injuria intra- } \\
\text { abdominal. Solo } \\
\text { detecta líquido } \\
\text { libre }(>200 \mathrm{ml})\end{array}$ \\
\hline FATE & $\begin{array}{l}\text { Modalidades } \\
\text { - 2-D } \\
\text { - Modo M } \\
\text { Visiones } \\
\text { PLAX, PSAX, } \\
\text { A4CH, S4CH, } \\
\text { Pleura }\end{array}$ & $\begin{array}{l}\text { Paro cardíaco, hipotensión } \\
\text { "inexplicable" }\end{array}$ & $\begin{array}{l}\text { - Excluye patologías obvias, evalúa tamaño y función } \\
\text { ventricular y visualiza pleura }\end{array}$ & $\begin{array}{l}\text { - Operador depen- } \\
\text { diente }\end{array}$ \\
\hline FEEL & $\begin{array}{l}\text { Modalidades } \\
-2-\mathrm{D} \\
\text { Visiones S4CH, } \\
\text { Opcional las } \\
\text { otras } \\
\text { ventanas } \\
\text { cardiacas }\end{array}$ & Paciente en PCR & - Evalúa causas de actividad eléctrica sin pulso & $\begin{array}{l}\text { - Operador depen- } \\
\text { diente }\end{array}$ \\
\hline RUSH & $\begin{array}{l}\text { Modalidades } \\
\text { - 2-D } \\
\text { Visiones } \\
\text { PLAX, PSAX, } \\
\text { A4CH, S4CH, } \\
\text { SIVC, CSD, CSI, } \\
\text { Pelvis, tórax }\end{array}$ & Paciente en Shock & $\begin{array}{l}\text { - Evalúa para fluido pericárdico, función sistólica } \\
\text { ventricular, estado de volemia, líquido pleural e } \\
\text { intraperitoneal, embolismo pulmonar, aneurisma } \\
\text { aórtico y TVP }\end{array}$ & $\begin{array}{l}\text { - Operador depen- } \\
\text { diente }\end{array}$ \\
\hline ACES & $\begin{array}{l}\text { Modalidades } \\
\text { - 2-D } \\
\text { - Modo M } \\
\text { Visiones } \\
\text { S4CH (otras si } \\
\text { ésta no se logra), } \\
\text { SIVC, ECAA, } \\
\text { CSD, CSI, pelvis }\end{array}$ & $\begin{array}{l}\text { Hipotensión indiferenciada } \\
\text { no traumática }\end{array}$ & $\begin{array}{l}\text { - Evalúa fluido pericárdico, función sistólica ventricu- } \\
\text { lar, estado de volemia, fluido pleural e intraperito- } \\
\text { neal, aneurisma aórtico abdominal }\end{array}$ & $\begin{array}{l}\text { - Operador depen- } \\
\text { diente }\end{array}$ \\
\hline BLUE & $\begin{array}{l}\text { Modalidades } \\
\text { - 2-D } \\
\text { - Modo M } \\
\text { Visiones } \\
\text { Puntos BLUE } \\
\text { superior e infe- } \\
\text { rior, más punto } \\
\text { PLAPS, bilateral }\end{array}$ & $\begin{array}{l}\text { Pacientes con insuficiencia } \\
\text { respiratoria aguda, disnea }\end{array}$ & $\begin{array}{l}\text { - Evalúa principales causas de insuficiencia respirato- } \\
\text { ria aguda mediante ultrasonido pulmonar y venoso }\end{array}$ & $\begin{array}{l}\text { - Operador depen- } \\
\text { diente }\end{array}$ \\
\hline FALL & $\begin{array}{l}\text { Modalidades } \\
\text { - 2-D } \\
\text { Visiones } \\
\text { Puntos BLUE } \\
\text { superior e infe- } \\
\text { rior, más punto } \\
\text { PLAPS, bilateral }\end{array}$ & Paciente en shock & $\begin{array}{l}\text { - Orienta sobre la idoneidad de aporte de volumen } \\
\text { como manejo del shock }\end{array}$ & $\begin{array}{l}\text { - Operador depen- } \\
\text { diente } \\
\text {-Acotado a evaluar } \\
\text { posibilidad de res- } \\
\text { puesta a volumen } \\
\text { y no causa del } \\
\text { shock }\end{array}$ \\
\hline
\end{tabular}

PLAX: Eje largo paraesternal; PSAX: Eje corto paraesternal; A4CH: 4 cámaras apical; SIVC: Visión subcostal vena cava inferior; CSD: cuadrante superior derecho; CSI: cuadrante superior izquierdo; ECAA: Eje corto aorta abdominal; Puntos BLUE y PLAPS: ver texto más adelante. 
1.-ACES: ABDOMINAL AND CARDIAC EVALUATION WITH SONOGRAPHY IN SHOCK

2.-RUSH: RAPID ULTRASOUND IN SHOCK

\section{3.-E-FAST: EXTENDED FOCUSED ASSESSMENT SONOGRAPHY FOR TRAUMA}

4.- FOCUS: FOCUSED CARDIAC ULTRASOUND

5.-FATE: FOCUS ASSESSED TRANSTHORACIC ECHOCARDIOGRAPHY

6.- FEEL: "FOCUSED ECHOCARDIOGRAPHIC EVALUATION IN LIFE SUPPORT

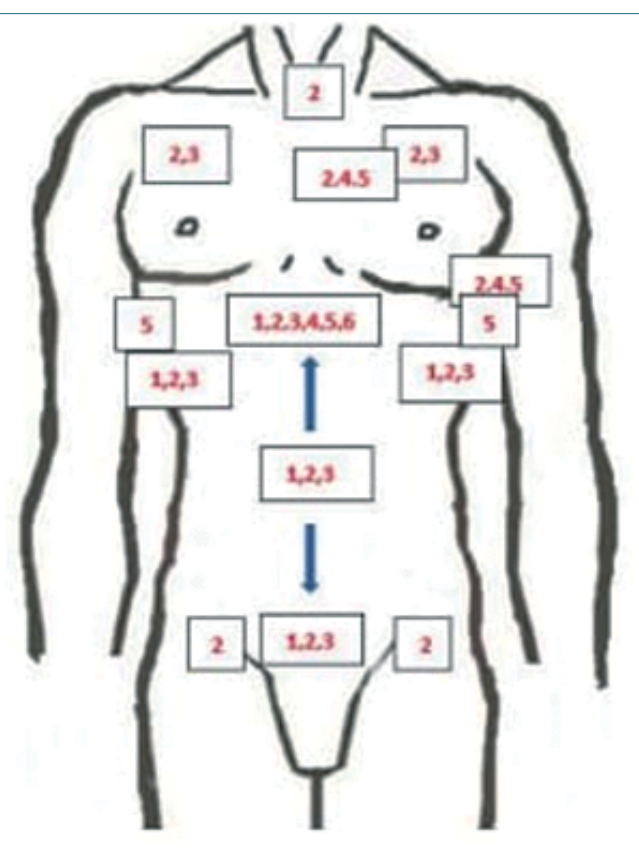

Figura 21. Principales ventanas utilizadas en protocolos acotados de ultrasonidos.

\section{Referencias}

1. Daniela Guzmán et al. Ecografía de Urgencia en Situaciones Tiempo Dependiente, Primera Edición año 2019.

2. Rene de la Fuente $S$, et al. Conceptos básicos de ultrasonografía aplicada a la anestesia regional. Rev Chil Anest. 2009;38:39-45.

3. Neal JM. A practical approach in Regional Anesthesiology and Acute Pain Medicine, Quinta edición. Editorial Wolters Kluwer; 2018.

4. Zimmerman JM, Coker BJ. The Nuts and Bolts of Performing Focused Cardiovascular Ultrasound (FoCUS). Anesth Analg. 2017 Mar;124(3):75360. https://doi.org/10.1213/ ANE.0000000000001861 PMID:28207445

5. Royse CF, Canty DJ, Faris J, Haji DL, Veltman M, Royse
A. Core review: physicianperformed ultrasound: the time has come for routine use in acute care medicine. Anesth Analg. 2012 Nov;115(5):100728. https://doi.org/10.1213/ ANE.0b013e31826a79c1 PMID:23011559

6. Peris A, Zagli G, Bonizzoli M, Cianchi G, Ciapetti M, Spina R, et al. Implantation of 3951 longterm central venous catheters: performances, risk analysis, and patient comfort after ultrasoundguidance introduction. Anesth Analg. 2010 Nov;111(5):1194201. https://doi.org/10.1213/ ANE.0b013e3181f333c1 PMID:20829559

7. Wigmore TJ, Smythe JF, Hacking MB, Raobaikady R, MacCallum NS. Effect of the implementation of NICE guidelines for ultrasound guidance on the complication rates associated with central venous catheter placement in patients presenting for routine surgery in a tertiary referral centre. $\mathrm{Br} J$ Anaesth. 2007 Nov;99(5):662-5. https:// doi.org/10.1093/bja/aem262 PMID:17872936

8. Terkawi AS, Karakitsos D, Elbarbary M, Blaivas M, Durieux ME; Abdullah S Terwaki et al. Ultrasound for the anesthesiologists: present and future. ScientificWorldJournal. 2013 Nov;2013:683685. https://doi. org/10.1155/2013/683685 PMID:24348179

9. Troianos CA, Hartman GS, Glas $K E$, Skubas NJ, Eberhardt RT, Walker JD, et al.; Councils on Intraoperative Echocardiography and Vascular Ultrasound of the American Society of Echocardiography; Society of Cardiovascular Anesthesiologists. Special articles: guidelines for performing ultrasound guided vascular cannulation: recom- 
mendations of the American Society of Echocardiography and the Society Of Cardiovascular Anesthesiologists. Anesth Analg. 2012 Jan;114(1):4672. https://doi.org/10.1213/ ANE.0b013e3182407cd8 PMID:22127816

10. Shiloh AL, Savel RH, Paulin LM, Eisen LA. Ultrasound-guided catheterization of the radial artery: a systematic review and meta-analysis of randomized controlled trials. Chest. 2011 Mar;139(3):524-9. https://doi. org/10.1378/chest.10-0919 PMID:20724734

11. Gu WJ, Wu XD, Wang F, Ma ZL, Gu XP. Ultrasound Guidance Facilitates Radial Artery Catheterization: A Meta-analysis With Trial Sequential Analysis of Randomized Controlled Trials. Chest. 2016 Jan;149(1):166-79. https:// doi.org/10.1378/chest.15-1784 PMID:26426094

12. Coker BJ, Zimmerman JM. Why Anesthesiologists Must Incorporate Focused Cardiac Ultrasound Into Daily Practice. Anesth Analg. 2017 Mar;124(3):761-

5. https://doi.org/10.1213/ ANE.0000000000001854 PMID:28207446

13. Spencer KT, Kimura BJ, Korcarz CE, Pellikka PA, Rahko PS, Siegel RJ. Focused cardiac ultrasound: recommendations from the American Society of Echocardiography. J Am Soc Echocardiogr. 2013 Jun;26(6):567-81. https://doi. org/10.1016/j.echo.2013.04.001 PMID:23711341

14. Via $G$, Hussain $A$, Wells $M$, Reardon R, ElBarbary M, Noble VE, et al. Hussain,Aet al. International Evidence-Based Recommendations for Focused Cardiac Ultrasound. J Am Soc Echocardiogr. 2014 Jul;27(7):683. e1-33. https://doi.org/10.1016/j. echo.2014.05.001.
15. Arntfield RT, Millington SJ. Point of care cardiac ultrasound applications in the emergency department and intensive care unit-a review. Curr Cardiol Rev. 2012 May;8(2):98-108. ttps://74/157340312801784952 PMID:22894759

16. Piette E, Daoust R, Denault A. Basic concepts in the use of thoracic and lung ultrasound. Curr Opin Anaesthesiol. 2013 Feb;26(1):20-30. https://doi.org/10.1097/ ACO.0b013e32835afd40 PMID:23103845

17. Lichtenstein $D$, Mezière $G$, Seitz J. The dynamic air bronchogram. A lung ultrasound sign of alveolar consolidation ruling out atelectasis. Chest. 2009 Jun;135(6):1421-5. https://doi. org/10.1378/chest.08-2281 PMID:19225063

18. Mayo PH, Doelken P. Pleural ultrasonography. Clin Chest Med. 2006 Jun;27(2):21527. https://doi.org/10.1016/j. ccm.2006.01.003 PMID:16716814

19. Volpicelli G, Elbarbary M, Blaivas $M$, Lichtenstein DA, Mathis $G$, Kirkpatrick AW, et al.; International Liaison Committee on Lung Ultrasound (ILC-LUS) for International Consensus Conference on Lung Ultrasound (ICC-LUS). International evidence-based recommendations for point-of-care lung ultrasound. Intensive Care Med. 2012 Apr;38(4):577-91. https://doi.org/10.1007/s00134012-2513-4 PMID:22392031

20. Azócar L. Uso de ecografía en anestesia: point of care Ultrasound (POCUS). Rev. Chil. Anest. 2017;46(3):157-66. https:// doi.org/10.25237/revchilanestv46n03.06.

21. Stefanidis K, Dimopoulos S, Nanas S. Basic principles and current applications of lung ultrasonography in the intensive care unit. Respirology. 2011 Feb;16(2):249-56. https://doi.org/10.1111/ j.1440-1843.2010.01885.x PMID:20969673

22. Alrajab S, Youssef AM, Akkus $\mathrm{NI}$, Caldito G. Pleural ultrasonography versus chest radiography for the diagnosis of pneumothorax: review of the literature and meta-analysis. Crit Care. 2013 Sep;17(5):R208. https://doi.org/10.1186/cc13016 PMID:24060427

23. Vignon $P$, Chastagner $C$, Berkane V, Chardac E, François B, Normand S, et al. Quantitative assessment of pleural effusion in critically ill patients by means of ultrasonography. Crit Care Med. 2005 Aug;33(8):175763. https://doi.org/10.1097/01. CCM.0000171532.02639.08 PMID:16096453

24. Ford JW, Heiberg J, Brennan AP et al. A Pilot Assessment of 3 Point -of-Care Strategies for Diagnosis of Perioperative Lung Pathology Anesth Analg 2017; 124: 734-42.

25. Perlas $A$, Van de Putte $P$, Van Houwe P, Chan VW. I-AIM framework for point-of-care gastric ultrasound. Br J Anaesth. 2016 Jan;116(1):7-11. https:// doi.org/10.1093/bja/aev113 PMID:25951832

26. Perlas A, Mitsakakis N, Liu L, Cino M, Haldipur N, Davis L, et al. Validation of a mathematical model for ultrasound assessment of gastric volume by gastroscopic examination. Anesth Analg. 2013 Feb;116(2):35763. https://doi.org/10.1213/ ANE.0b013e318274fc19 PMID:23302981

27. Spencer $A O$, Walker $A M$, Yeung AK, Lardner DR, Yee K, Mulvey $J M$, et al. Ultrasound assessment of gastric volume in the fasted pediatric patient undergoing upper gastrointestinal endosco- 
py: development of a predictive model using endoscopically suctioned volumes. Paediatr Anaesth. 2015 Mar;25(3):3018. https://doi.org/10.1111/ pan.12581 PMID:25495405

28. Scalea TM, Rodríguez A, Chiu WC, Brenneman FD, Fallon WF Jr, Kato K, et al. Focused Assessment with Sonography for Trauma (FAST): results from an international consensus conference. J Trauma. 1999 Mar;46(3):466-72. https:// doi.org/10.1097/00005373199903000-00022 PMID:10088853

29. Mayo PH. Ultrasonography: fundamentals in critical care ultrasound [course material]Baltimore (MD): American College of Chest Physicians; 2011.

30. Lee CW, Kory PD, Arntfield RT. Development of a fluid resuscitation protocol using inferior vena cava and lung ultrasound. J Crit Care. 2016 Feb;31(1):96-100. https://doi. org/10.1016/j.jcrc.2015.09.016 PMID:26475100

31. Barbier $C$, Loubières $Y$, Schmit $C$, Hayon J, Ricôme JL, Jardin F, et al. Respiratory changes in inferior vena cava diameter are helpful in predicting fluid responsiveness in ventilated septic patients. Intensive Care Med. 2004 Sep;30(9):1740-6. https://doi. org/10.1007/s00134-004-22598 PMID:15034650

32. Feissel $M$, Michard $F$, Faller JP, Teboul JL. The respiratory variation in inferior vena cava diameter as a guide to fluid therapy. Intensive Care Med. 2004
Sep;30(9):1834-7. https://doi. org/10.1007/s00134-004-22335 PMID:15045170

33. Kristensen MS. Ultrasonography in the management of the airway. Acta Anaesthesiol Scand. 2011 Nov;55(10):115573. https://doi.org/10.1111/ j.1399-6576.2011.02518.x PMID:22092121

34. Rudraraju P, Eisen LA. Confirmation of endotracheal tube position: a narrative review. J Intensive Care Med. 2009 SepOct;24(5):283-92. https://doi. rg/10.1177/0885066609340501 PMID:19654121

35. Ramsingh $D$, Frank $E$, Haughton R, Schilling J, Gimenez KM, Banh $E$, et al. Auscultation versus Point-of-care Ultrasound to Determine Endotracheal versus Bronchial Intubation: A Diagnostic Accuracy Study. Anesthesiology. 2016 May; 124(5):101220. https://doi.org/10.1097/ ALN.0000000000001073 PMID:26950708

36. Green JS, Tsui BC. Applications of ultrasonography in ENT: airway assessment and nerve blockade. Anesthesiol Clin. 2010 Sep;28(3):54153. https://doi.org/10.1016/j. anclin.2010.07.012 PMID:20850084

37. Kaur B, Tang R, Sawka A, Krebs C, Vaghadia H. A method for ultrasonographic visualization and injection of the superior laryngeal nerve: volunteer study and cadaver simulation. Anesth Analg. 2012 Nov;115(5):12425. https://doi.org/10.1213/ ANE.0b013e318265f75d
PMID:22822197

38. Brodsky JB, Macario A, Mark JB. Tracheal diameter predicts double-lumen tube size: a method for selecting left double-lumen tubes. Anesth Analg. 1996 Apr;82(4):861-4. PMID:8615510

39. Brodsky JB, Malott K, Angst M, Fitzmaurice BG, Kee SP, Logan $L$. The relationship between tracheal width and left bronchial width: implications for left-sided double-lumen tube selection. J Cardiothorac Vasc Anesth. 2001 Apr;15(2):216-7. https://doi. org/10.1053/jcan.2001.21970 PMID:11312482

40. Rajajee V, Fletcher JJ, Rochlen LR, Jacobs TL. Real-time ultrasoundguided percutaneous dilatational tracheostomy: a feasibility study. Crit Care. 2011;15(1):R67. https://doi.org/10.1186/cc10047 PMID:21342494

41. Ochoa-Pérez L, Cardozo-Ocampo A. Aplicaciones de la ultrasonografía en el sistema nervioso central para neuroanestesia y cuidado crítico. Rev Colomb Anestesiol. 2015;43(4):31420. https://doi.org/10.1016/j. rca.2015.03.009.

42. Dubost C, Geeraerts T. Possible pitfalls when measuring the optic nerve sheath with sonography. J Surg Res. 2012 Mar;173(1):e43-4. https://doi. org/10.1016/j.jss.2011.08.027 PMID:22221601

43. Ursprung $E$, Oren-Grinberg A. Point-of-Care Ultrasound in the Perioperative Period. Int Anesthesiol Clin. 2016;54(1):121. https://doi.org/10.1097/ AIA.0000000000000084 PMID:26655506 